\title{
Three-Dimensional Flow of a Vortex Drop Shaft Spillway with an Elliptical Tangential Inlet
}

\author{
Zhou Yang, Jinbu Yin *(D), Yangliang Lu, Zhiming Liu, Haoyu Yang and Genhai Xu \\ College of Water Resources and Architectural Engineering, Northwest A\&F University, Weihui Road, \\ Yangling 712100, China; yangzsks@nwafu.edu.cn (Z.Y.); slgclyl@163.com (Y.L.); zmliu@nwsuaf.edu.cn (Z.L.); \\ sjxyyanghaoyu@nwafu.edu.cn (H.Y.); xugen-hai@163.com (G.X.) \\ * Correspondence: xnsj-y@nwafu.edu.cn; Tel.: +86-136-0925-9097
}

check for updates

Citation: Yang, Z.; Yin, J.; Lu, Y.; Liu, Z.; Yang, H.; Xu, G. Three-

Dimensional Flow of a Vortex Drop Shaft Spillway with an Elliptical Tangential Inlet. Water 2021, 13, 504. https://doi.org/10.3390/w13040504

Received: 16 January 2021

Accepted: 11 February 2021

Published: 15 February 2021

Publisher's Note: MDPI stays neutral with regard to jurisdictional claims in published maps and institutional affiliations.

Copyright: (c) 2021 by the authors. Licensee MDPI, Basel, Switzerland. This article is an open access article distributed under the terms and conditions of the Creative Commons Attribution (CC BY) license (https:// creativecommons.org/licenses/by/ $4.0 /)$.

\begin{abstract}
Vortex drop shaft (VDS) spillways are eco-friendly hydraulic structures used for safely releasing flood. However, due to the complexity of the three-dimensional rotational flow and the lack of suitable measuring devices, current experimental work cannot interpret the flow behavior reliably inside the VDS spillway, consequently experimental and CFD study on a VDS spillway with an elliptical tangential inlet was conducted to further discern the interior three-dimensional flow behavior. Hydraulic characteristics such as wall pressure, swirl angle, annular hydraulic height and Froude number of the tapering section are experimentally obtained and acceptably agreed with the numerical prediction. Results indicated that the relative dimensionless maximum height of the standing wave falls off nearly linearly with the increasing Froude number. Nonlinear regression was established to give an estimation of the minimum air-core rate. The normalized height of the hydraulic jump depends on the flow phenomena of pressure slope. Simulated results sufficiently reveal the three-dimensional velocity field (resultant velocity, axial velocity, tangential velocity and radial velocity) with obvious regional and cross-sectional variations inside the vortex drop shaft. It is found that cross-sectional tangential velocity varies, resembling the near-cavity forced vortex and near-wall free vortex behavior. Analytic calculations for the cross-sectional pressure were developed and correlated well with simulated results.
\end{abstract}

Keywords: numerical simulation; VDS; elliptical tangential inlet; air core; velocity; combined vortex distribution

\section{Introduction}

Vortex drop shaft (VDS) spillways are widely used discharge structures in China owing to various excellent performances, such as high-energy dissipation, steady flow regime and good terrain adaptability [1]. Additionally, compared with traditional ski-jump energy dissipaters, VDS spillways can transfer the flood discharge and energy dissipation task into the tunnel, which effectively avoids outlet atomization formed by the interaction between air boundary water and reduces the impact on the ecological environment $[2,3]$. Examples of existing VDS spillway include Shapai, China [4], Xiaowan, China [5], Jiayan, China [6], etc. While for other countries, such structures are now commonly applied in urban drainage systems to convey sewage or surface runoff from different levels $[7,8]$. Regardless of different application purpose, the investigation focused on the general structure, and flow characteristics have many similarities.

Typical design components for the VDS include an inlet structure, a vertical structure and an outlet structure. Inlet structures are mainly classified into the three forms: (a) tangential inlet [9], (b) vortex slot inlet [10], and (c) spiral inlet [11]. The intake structure aims to directly transform horizontal or sloping flow into a stable helicoidal flow and to maintain a stable air core, leaving enough space for the air to escape [12,13]. Extensive experimental and theoretical studies have been conducted to determine the flow properties of the inlet structures. Early Slisskii and Kuznetsov [14] reported a simple hydraulic model 
study for the Medo dam with a tangential inlet. A depth-discharge theoretical model was first proposed by Jain [9] to predict the flow depth for the tangential inlet. Yu and Lee [15] demonstrated that the hydraulic stability in the vortex inlet was strongly related to the geometry of the inlet and vertical shaft, and a comprehensive theoretical design guideline for the tangential slot intake was proposed. Del Giudice [16] recommended the improved design of the inlet in which proper reduction of the bottom length could prevent hydraulic jump and congestion phenomenon. Pfister and Crispino [13] presented an applicable concept to a novel junction chamber combining with several inlet channels. In addition, Hager [11], Crispino and Pfister [17], and Wu et al. [18] theoretically and experimentally analyzed the performance of the standing wave at the intake structure, mainly characterized by the relative height, the location and the extent.

The vertical structure is next to the inlet structure, where the flow clings to the wall and swirls down along the wall at the mercy of centrifugal force and gravity [19]. Moreover, there are remarkable energy dissipation and air entrainment associated with the flow pattern alteration. According to the experimental results of Jain, flow in the vertical drop shaft can be distinguished into three regions, annular jet flow, transition flow, and water cushion region [20]. The investigation of the aeration and the deaeration processes is extremely necessary when the vertical shaft structure is considered. Dynamic change of the air entrainment in the high drop shaft would generate system pressurization and then release foul-smelling air [21]. Li et al. [22] emphasized the need for an aerator in the middle of the shaft, and a calculation method for aeration cavity length was presented. However, both experimental and numerical simulation results on the air entrainment differed from prototype values $[23,24]$. Although a model with gravity similarity criterion could simulate well the water flow, it did not adequately simulate the entrainment and transport of the air [25]. Other studies focused on energy loss found that depth of energy dissipation well has little effect on total energy dissipation rate and that the energy dissipation rate of the rotational flow is much smaller than that of the annular hydraulic jump in dissipation well $[26,27]$. Generally, the total energy dissipation ratio can exceed $70 \%$ under a reasonable design $[26,28,29]$. In other studies, the characteristics of velocity and pressure on a level swirling flow discharge tunnel were theoretically analyzed based on the combined vortex rule [30-33].

The outlet structure is mainly set to alter the flow pattern from annular flow to horizontal flow without severe water surface fluctuations. Nevertheless, limited laboratory studies had been done for outlet structure. Del Giudice and Gisonni [7] carried out some preliminary exploration in terms of both optimizing outlet shape and improving energy dissipation. Zhang et al. [34] developed a novel type of submerged outlet for the VDS spillways, where the flow transit smoothly and favorably from non-pressure flow to pressure flow.

Overall, it can be said that previous advance made on the different parts and research aspects of the VDS was considerable. However, unlike the previous VDS with a tangential slot inlet $[9,15,29]$, widely applied in an urban drainage system, the hydraulic behavior of a VDS spillway equipped with an elliptical tangential inlet has not been detailed addressed. Such shape originated in China, and it is generally considered superior with better discharge capacity and flow pattern than the former [1]. On the one hand, the elliptical tangential inlet can promote the formation of a stable rotational flow under various flow conditions, while for the tangential slot inlet, the overfall flow phenomenon will directly occur under small flow conditions. On the other hand, the flow in the elliptical intake is smoother because of the elliptical guiding wall, and it is not prone to cause backwater and negative pressure. Benefiting from the above, a similar VDS spillway with the elliptical tangential inlet has already been built in China, such as Xiaowan and Jilintai. Previously Wei et al. [35] have theoretically proposed the design criteria for this shape. Moreover, due to the complexity of the three-dimensional rotational flow and the lack of suitable measuring devices, detailed information such as the three-dimensional velocity field inside the VDS spillway is hitherto lacking. Fortunately, numerical simulation is 
able to reproduce the experimental flow phenomena while straightforward obtaining the detailed hydraulic parameter inside the VDS. Recently, Liu et al. [2] have reported the successful use of the RNG $k-\varepsilon$ turbulence model on a newly developed VDS spillway with the spiral-flow-generating piers. However, there are also no detailed three-dimensional flow characteristics.

Hence, in the present study, physical model experiments with corresponding numerical simulation were conducted to further discern the three-dimensional flow behavior of a VDS spillway, comprising a tangential vortex intake with $1 / 4$ ellipse guiding wall, and the relevant computational results are verified by experimental data. Meanwhile, experimental and simulated results such as the performance of the standing wave, air-core ratio, cross-sectional pressure and three-dimensional velocity were comprehensively analyzed. Furthermore, the combined vortex rule was introduced to predict the cross-sectional pressure distribution of the swirling flow in the VDS. The outcomes of the current research can provide comprehensive insights for the research and application of similar engineering.

\section{Physical Model and Measurement}

A 1:40 Froude model fabricated from transparent plexiglass was made in the College of Water Resources and Architectural Engineering, Northwest A\&F University, to provide a useful reference for future prototype VDS spillways serving in China. Generally, the scale effect can be ignored for some time-averaged hydraulic characteristics [36]. The physical model consists of an elliptical tangential inlet (include a tapering section and a vortex chamber), a gradient (contracted) section, a vertical shaft, an energy dissipation well, a pressure slope and an outlet tunnel, as shown in Figure 1, in which the vortex chamber, gradient section, vertical shaft, dissipation well can be collectively referred to as the VDS.

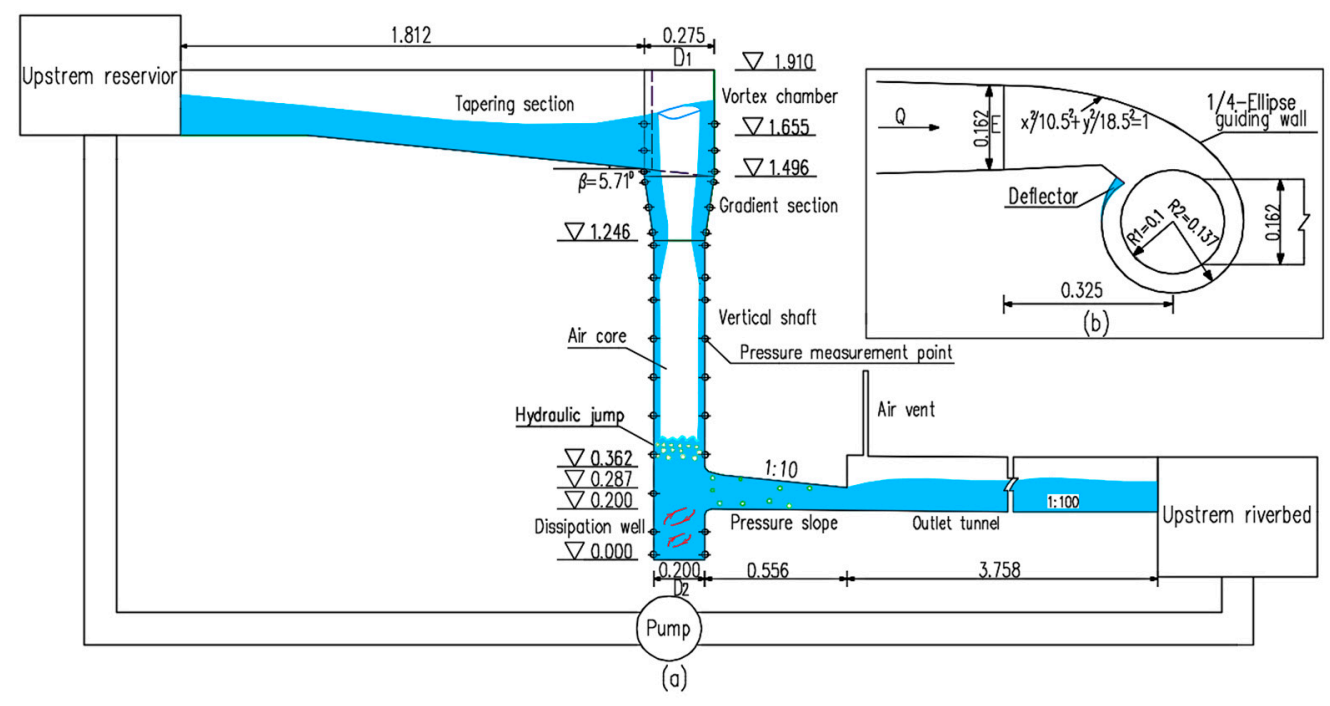

Figure 1. (a) Side view of the experimental setup; and (b) elliptical inlet configuration (all dimensions are in meters).

Unlike the previous tangential slot inlet where the tapering section and the vortex chamber are directly tangential connected in a straight line is widely applied in urban drainage systems. In this study, an elliptical tangential inlet equipped with a $1 / 4$ elliptical guiding wall $\left(x^{2} / 10.5^{2}+y^{2} / 18.5^{2}=1\right)$ was applied, as shown in Figure 1. Additionally, a deflector was set in the vortex chamber to prevent the backwater phenomenon. The inclination angle $(\beta)$ of the tapering section is 5.71 degrees, and the entrance width (E) of the vortex chamber is $0.162 \mathrm{~m}$. The diameter of the vortex chamber $\left(D_{1}\right)$ and vertical shaft $\left(D_{2}\right)$ is $0.275 \mathrm{~m}$ and $0.2 \mathrm{~m}$ separately. The total height of the VDS is $1.91 \mathrm{~m}$. A more detailed dimension is shown in Figure 1. In order to better understand the hydraulic behavior, a total of five experimental flow rates were considered, namely $45.46 \mathrm{~L} / \mathrm{s}, 40.52 \mathrm{~L} / \mathrm{s}, 24.11$ $\mathrm{L} / \mathrm{s}, 20.26 \mathrm{~L} / \mathrm{s}$ and $17.59 \mathrm{~L} / \mathrm{s}$, corresponding to flood frequency $\mathrm{P}=0.05 \%, \mathrm{P}=0.1 \%, \mathrm{P}=1 \%$, 
$\mathrm{P}=2 \%$ and $\mathrm{P}=3.3 \%$, respectively, and the first 3 test-runs $(\mathrm{P}=0.05 \%, 0.1 \%, 1 \%$, respectively $)$ were simulated.

In this experiment, a steady discharge generated by a recirculating flow system was provided to guarantee the rigor and repeatability of the experiments, as simply shown in Figure 1. The discharge was measured by a rectangular weir. Piezometers were used for acquiring time-average pressure values of the wall. Due to the pulsation of water flow at dissipation well, a possibly largest pressure error of $\pm 10 \%$ was estimated, and the error range of the remaining points was estimated to be within plus or minus $3 \%$. The location of measuring points is as shown in Figure 1. The velocity at the tapering section was detected using a propeller-type current meter (relative error $\leq \pm 5 \%$ ). The measuring points are, respectively, taken at a distance of about $1.5 \mathrm{~cm}$ from the water surface and the bottom and taken in the middle. The average velocity can be obtained through the above three sets of data. The near-wall swirl angle was measured by the tracer method with a protractor, and the accuracy is 1 degree. Given the available measuring devices and laboratory limitations, three sets of measurements were taken, and the experimental data were averaged.

Inside the VDS, the hydraulic behavior of the numerical model is similar. However, in that region, the laboratory measurements such as the pitot tube may be affected by the turbulently uneven water thickness and misaligned direction, which might result in an error up to $20-30 \%$ [31]. Hence, the flow velocity in this research was supplemented by numerical simulation.

\section{Numerical Simulation}

\subsection{Governing Equations}

Although the $k-\varepsilon$ turbulent models have been widely applied to flow simulations because of the fine convergence and computational efficiency [37-39], the RNG $k-\varepsilon$ turbulence model proposed by Yakhot and Orzag, by providing an additional coefficient correcting the turbulent viscosity and taking into account the average rotational motion, can effectively process the strong swirling flow or curved wall jet under high Reynolds number [40]. Furthermore, regarding to previous research $[2,24,41]$ were found that the RNG $k-\varepsilon$ turbulence model can give the best prediction of the jet flow in such shaft spillway. Accordingly, this turbulence model was utilized to model the intricate flow in the VDS spillways via ANSYS 16.0 software, Fluent. The basic control equations are as follows:

Continuity Equation:

$$
\frac{\partial u_{i}}{\partial x_{i}}=0
$$

Momentum Equation:

$$
\frac{\partial u_{i}}{\partial t}+u_{j} \frac{\partial u_{i}}{\partial x_{j}}=-\frac{1}{\rho} \frac{\partial P}{\partial x_{i}}+v \frac{\partial^{2}}{\partial x_{i}} \frac{\partial u_{i}}{\partial x_{j}}+f_{i}
$$

$k$ Equation:

$$
\frac{\partial(\rho k)}{\partial t}+\frac{\partial\left(\rho u_{i} k\right)}{\partial x_{i}}=\frac{\partial}{\partial x_{j}}\left(\alpha_{k} \mu_{e f f} \frac{\partial k}{\partial x_{j}}\right)+G_{k}+\rho \varepsilon
$$

$\varepsilon$ Equation:

$$
\frac{\partial(\rho \varepsilon)}{\partial t}+\frac{\partial\left(\rho u_{i} \varepsilon\right)}{\partial x_{i}}=\frac{\partial}{\partial x_{j}}\left(\alpha_{\varepsilon} \mu_{e f f} \frac{\partial \varepsilon}{\partial x_{j}}\right)+\frac{C_{1 \varepsilon}^{*}}{k} G_{k}-C_{2 \varepsilon} \rho \frac{\varepsilon^{2}}{k}
$$

where $u_{i}$ is the velocity component in $x_{i}$ direction; $t$ is the time; $\rho$ and $v$ are the density and the kinematic viscosity coefficient of water, respectively. $\mathrm{P}$ is the corrected pressure; $f_{i}$ is the external volume force component; $\partial k$ and $\partial \varepsilon$ are the turbulent Prandtl constant; $G_{k}$ is the turbulent kinetic energy generated by the velocity gradient; $\mu_{e f f}$ is the corrected effective turbulent viscosity. $\mu_{e f f}=\mu+\mu_{t} \mu_{t}=\rho C_{\mu} \frac{k^{2}}{\varepsilon} G_{k}=\mu_{t}\left(\frac{\partial u_{i}}{\partial x_{j}}+\frac{\partial u_{i}}{\partial x_{i}}\right) \frac{\partial u_{i}}{\partial x_{j}} C_{1 \varepsilon}^{*}=C_{1 \varepsilon}-\frac{\eta\left(1-\eta / \eta_{0}\right)}{1+\beta \eta^{3}}$ 
$\eta=\left(2 E_{i j} \times E_{i j}\right)^{1 / 2} \frac{k}{\varepsilon} E_{i j}=\frac{1}{2}\left(\frac{\partial u_{i}}{\partial x_{j}}+\frac{\partial u_{j}}{\partial x_{i}}\right) \alpha_{k}=\alpha_{\varepsilon}=1.39 C_{\mu}=0.0845 C_{1 \varepsilon}=1.42 C_{2 \varepsilon}=1.68$ $\eta_{0}=4.377 \beta=0.012[42]$.

The VOF method presented by Hirt and Nichols [43] was used to catch the free surface of the high-speed flow, which is achieved by resolving the following Equation:

$$
\frac{\partial a_{w}}{\partial t}+u_{i} \frac{\partial a_{w}}{\partial x_{i}}=0
$$

where $a_{w}$ is the volume fraction of water.

\subsection{Mesh and Boundary Conditions}

The simulated domain with the same size as the physical model is shown in Figure 2. The origin of the coordinate system is set at the center of the bottom dissipation well. In the present simulation, a combination of structured and unstructured grids was utilized to mesh different parts of the VDS spillways. The well adaptable unstructured grids were applied for the VDS, and the grids were properly refined to ensure accuracy. The structural mesh was used for other parts. The partial meshing of the calculated domain is shown in Figure 2.

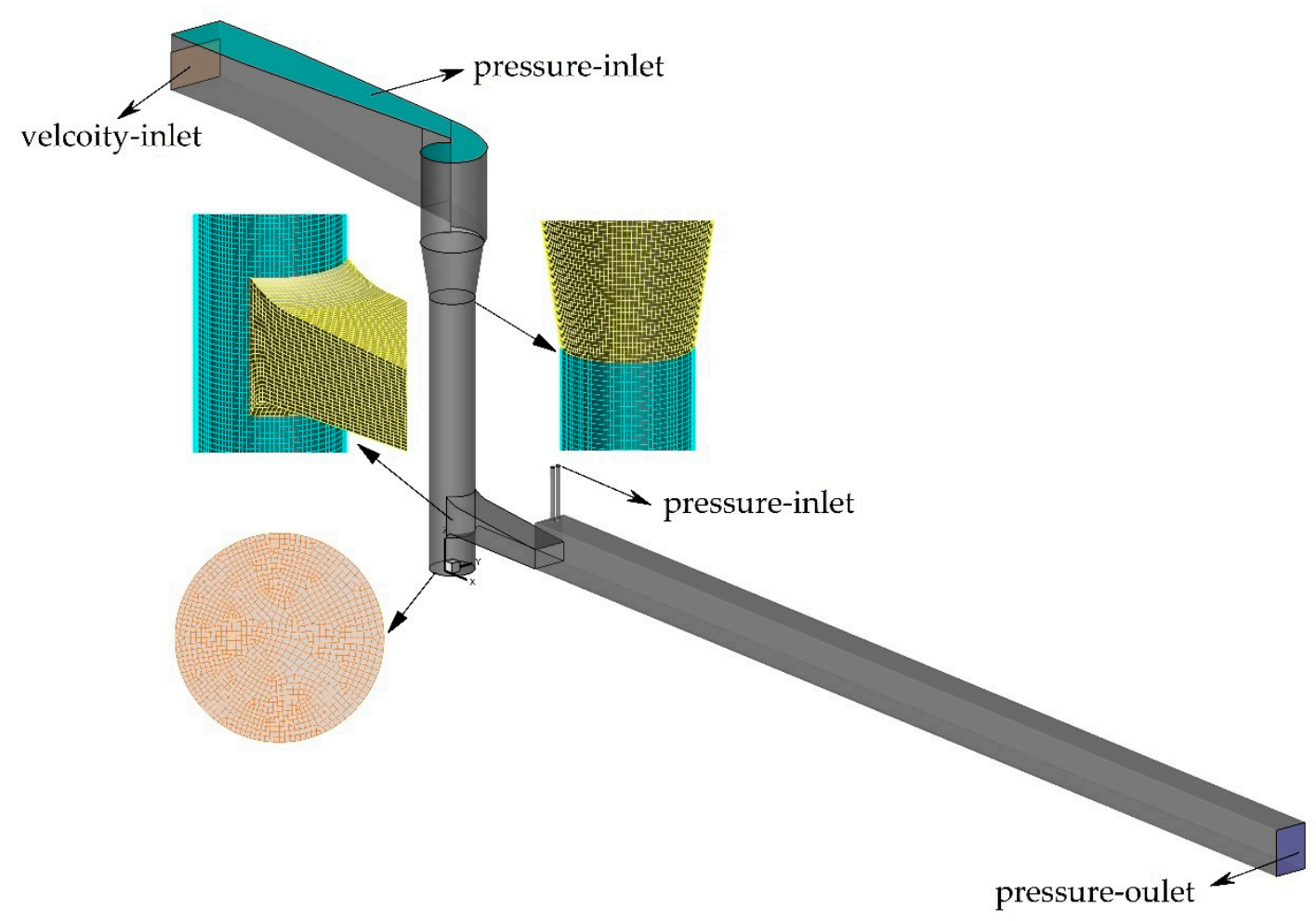

Figure 2. Boundary conditions and mesh.

Mesh convergence is tested under four grid densities at the flood frequency of $0.05 \%$; the results are shown in Table 1. It can be seen that the predicted outlet average velocity between mesh Scheme 3 and Scheme 4 shows less than a difference of $7.5 \%$ to the laboratory data and a relative error of $2.3 \%$, suggesting that both grid densities are practically available. Scheme 3 was eventually selected to save calculation time. Table 2 shows the comparison of experimental and simulated outlet average velocity based on the grid Scheme 3 under different flood conditions. The small deviations that are also visible once again prove that grid Scheme 3 is reliable. 
Table 1. The test of fine-grid selection $(P=0.05 \%)$.

\begin{tabular}{|c|c|c|c|c|c|}
\hline Mesh Scheme & Mesh Number & Mesh Size Range & $\begin{array}{l}\text { Outlet Average } \\
\text { Velocity }(\mathrm{m} / \mathrm{s})\end{array}$ & Relative Error & $\begin{array}{c}\text { Experimental Average } \\
\text { Velocity }(\mathrm{m} / \mathrm{s})\end{array}$ \\
\hline 1 & 374,240 & $12.5-25.0 \mathrm{~mm}$ & 3.44 & - & \multirow{4}{*}{2.82} \\
\hline 2 & 530,853 & $8.0-20.0 \mathrm{~mm}$ & 3.18 & 0.076 & \\
\hline 3 & 781,526 & $5.0-15.0 \mathrm{~mm}$ & 3.05 & 0.041 & \\
\hline 4 & 131,3582 & $2.5-10.0 \mathrm{~mm}$ & 2.98 & 0.023 & \\
\hline
\end{tabular}

Table 2. Simulation cases.

\begin{tabular}{|c|c|c|c|c|c|}
\hline \multirow{2}{*}{ Flood Frequency } & \multirow{2}{*}{ Inlet Water Depth (m) } & \multirow{2}{*}{ Inlet Velocity $(\mathrm{m} / \mathrm{s})$} & \multicolumn{2}{|c|}{ Outlet Velocity $(\mathrm{m} / \mathrm{s})$} & \multirow{2}{*}{ Deviation } \\
\hline & & & Simulation & Experiment & \\
\hline $1 \%$ & 0.108 & 0.812 & 2.12 & 2.03 & $4.26 \%$ \\
\hline $0.1 \%$ & 0.155 & 0.951 & 2.89 & 2.71 & $6.23 \%$ \\
\hline $0.05 \%$ & 0.173 & 0.956 & 3.05 & 2.82 & $7.54 \%$ \\
\hline
\end{tabular}

The boundary conditions are set as shown in Figure 2. For the water inlet, the flow depth and velocity were selected while the pressure-outlet prescribed with 0 gauge pressure was defined. Additionally, the pressure-inlet was adopted for the two air vents. The wall boundary was based on no-slip conditions, and a standard wall function was used for processing the area near the wall.

The governing equations are solved using the finite volume method; the pressurevelocity coupling adopts the well-established PISO algorithm; a quick scheme is used for momentum, a geo-reconstruct scheme for the volume fraction, and a second-order upwind scheme for the turbulent kinetic energy. The density and the kinematic viscosity coefficient of water are $998.2 \mathrm{~kg} / \mathrm{m}^{3}$ and $1.00310^{-3} \mathrm{~N} \cdot \mathrm{s} / \mathrm{m}^{2}$, respectively. A transient simulation using a variable time step was performed until the residual error was within $10^{-4}$. A group of successful simulation required about 50-60 s (approximately runs for 12 days), and three sets of stable computational results were averaged for different parameters.

\section{Results and Discussion}

\subsection{Flow Pattern in the Vortex Drop Shaft \\ 4.1.1. Standing Shock Wave}

Experimental observation and numerical prediction for flow state in the elliptical tangential inlet are shown in Figure 3. The figure reveals that the flow at long tapering section can be viewed as the rectangular open channel flow. The Froude number $(F r)$ calculated by $\mathrm{F}_{r}=v / \sqrt{g h}$ is also plotted in Figure 4 , which reduces with increasing discharge. It can be noted that the experimental results are in acceptable agreement with the numerical prediction (percentage error less than 9.12\%). For all flow cases, the approach flow is supercritical within the entire tapering section, where Fr is larger than 1. 


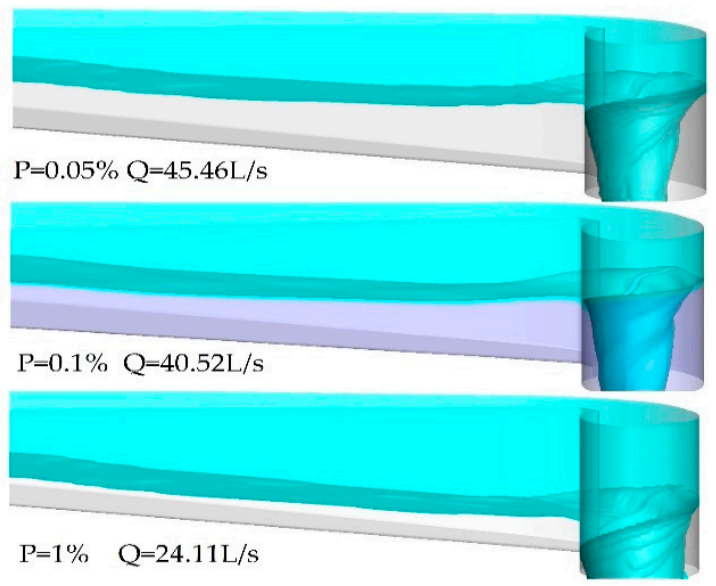

(a)
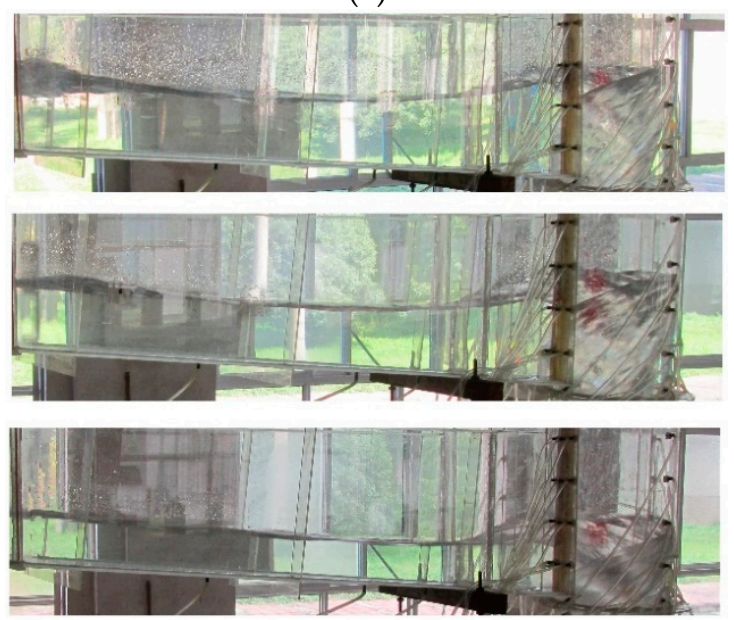

(b)

Figure 3. Flow pattern for the elliptical tangential inlet (a) predicted flow state (b) experimental flow observation.

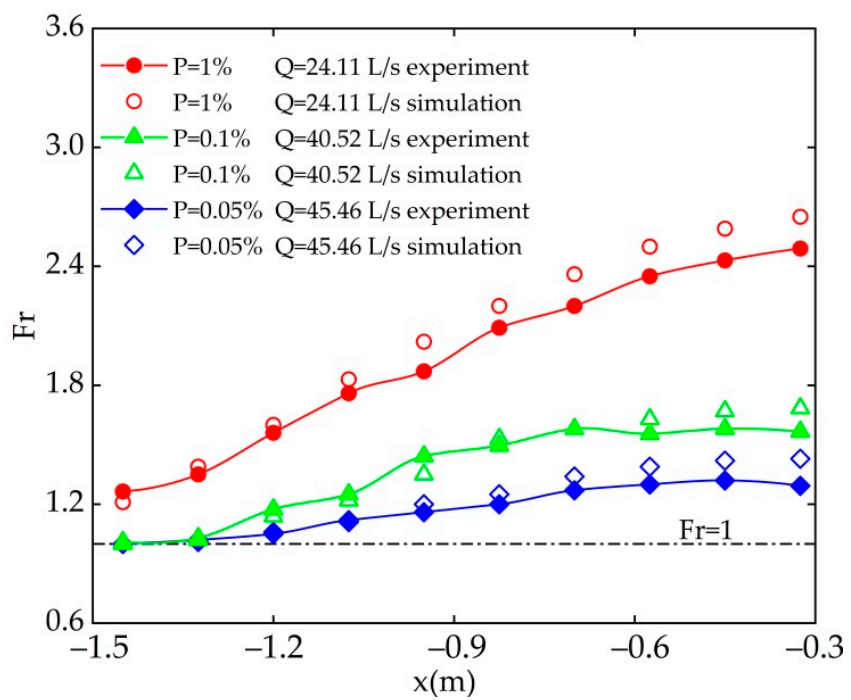

Figure 4. Froude number in the tapering section.

After the flow entered the vortex chamber with a $1 / 4$ elliptical guiding wall, the water surface elevation had a rising process due to flow deflection, generating one visible 
standing shock wave along the guiding wall, as observed in Figure 3. According to the experimental data in previous research [11], the shock wave was characterized by the maximum shock wave elevation $\left(h_{m}\right)$ for the spiral inlet, whereas few experimental data are available for the elliptical tangential intake. In the present investigation, the performance of the maximum height of the standing wave is expressed as a dimensionless parameter $\eta_{m}$ (relative maximum height $\eta_{m}=\left(h_{m}-h_{0}\right) / D_{1}$, where $h_{m}, h_{0}$ and $D_{1}$ is the maximum standing wave elevation, the water depth at the beginning of the elliptical guiding wall and the diameter of the vortex chamber, respectively, as shown in Figure 5.

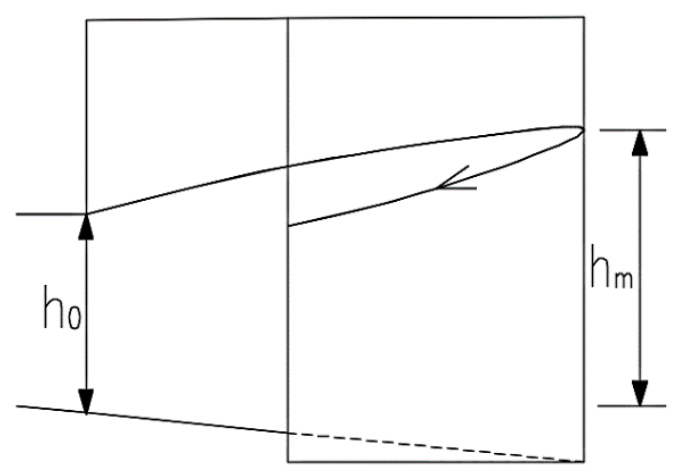

Figure 5. Standing wave along the guiding wall.

The dimensionless parameter $\eta_{m}$ at the elliptical tangential inlet is plotted as a function of $F r_{0}$ at the beginning of the elliptical guiding wall in Figure 6. It is shown from this figure that with increasing the $F r_{0}$ (approximately $F r_{0}=1-4$ ) or equivalently the decrease of discharge, the $\eta_{m}$ tends to linearly reduce. The linear regression is presented in Equation (6) with $R^{2}=0.987$. For spiral inlet with the supercritical flow, Crispino [17] stated that the shock wave maxima also depends on the $F r_{0}$ with a linear trend when not considering other geometric parameters, expressed as $h_{m} / h_{0}=2.3 F r_{0}$. Interestingly, as the experimental discharge increases from $17.59 \mathrm{~L} / \mathrm{s}\left(F r_{0}=4.02\right)$ to $45.46 \mathrm{~L} / \mathrm{s}\left(F r_{0}=1.29\right)$ about 2.5 times, the increasing effect of $\eta_{m}$ is insignificantly improved, which increases $35 \%$ from $0.212-0.286$.

$$
\eta_{\mathrm{m}}=-0.028 F r_{0}+0.323
$$

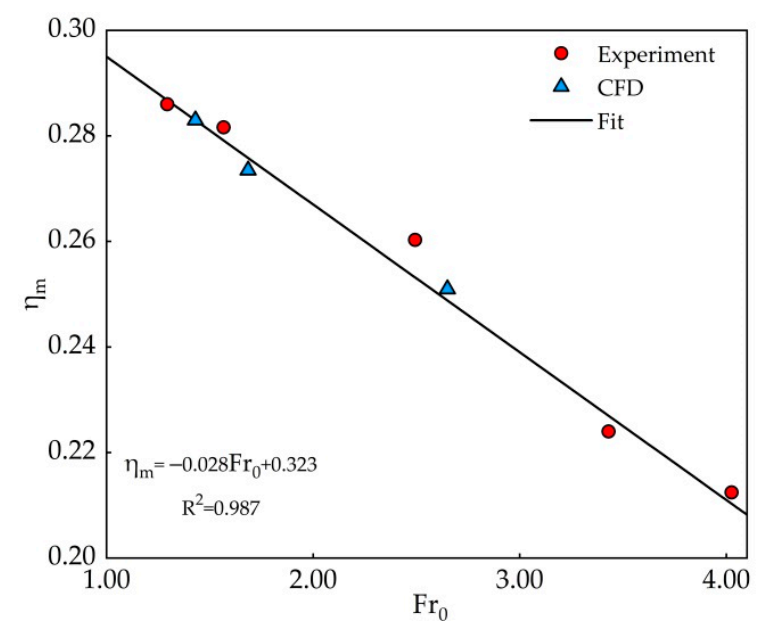

Figure 6. Relative maximum height against $F r_{0}$.

Equation (6) is based on the present geometric model and data, and it can be used to provide a reference for the tangential inlet with an elliptical guiding wall. Meanwhile, more experimental work by varying discharge, bottom slope and elliptical form is necessary to further discern this behavior. 


\subsubsection{Air Core}

The vortex chamber forces the approach flow to the spiral down and adheres to the wall, forming a stable cavity along the vertical axis. Figure 7 shows the experimental and predicted air core. The numerical prediction is able to overcome the test limitation inside the VDS and clearly capture the vertical variation, as shown in Figure $7 \mathrm{~b}$. The air core was hardly to be symmetrical because of the non-axisymmetric tangential inlet, resulting in uneven distribution of water layers in different cross-sections. Accordingly, the rotary flow can be divided into the main flow with thicker water layers and the non-main flow with the relatively thin water layers. According to the location change of the main flow in Figure $7 \mathrm{~b}$, it can be estimated that water rotated close to about 1 circle in the VDS. Overall, the simulation was able to reproduce the experimental flow phenomena while straightforward showing the flow regime of the rotary flow inside the VDS.

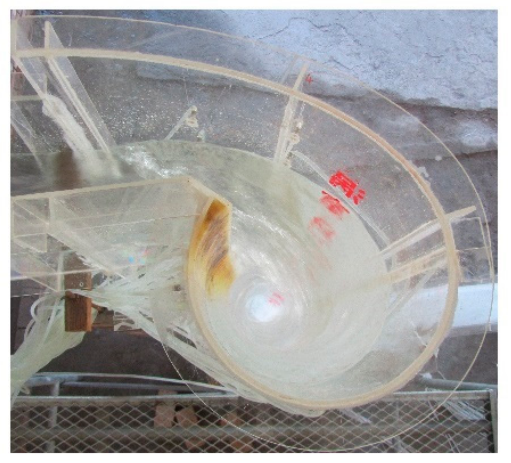

(a)

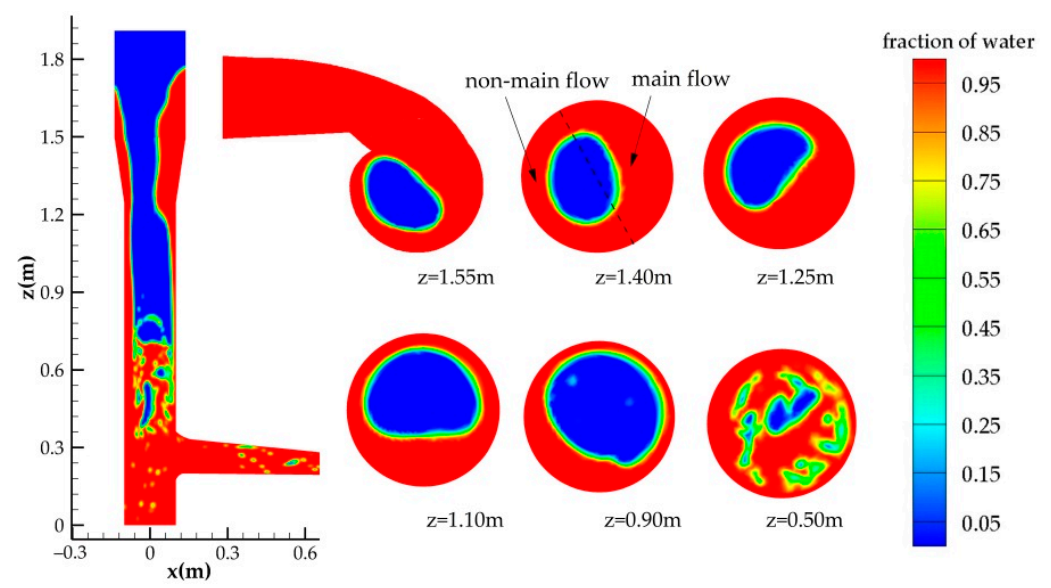

(b)

Figure 7. Air core in the vortex drop shaft $(\mathrm{P}=0.05 \%)$. (a) Rotary flow for test $(\mathbf{b})$ predicted air core of cross-sections.

Figure 8 shows the predicted air-core ratio $\lambda$ (ratio of the air-core area to cross-sectional area) in the contracted section and vertical shaft, showing an increasing trend of $\lambda$ with decreasing discharge. It can be seen that $\lambda$ was the smallest around the junction with a value larger than the minimum engineering requirement of 0.25 , indicating that the structure can meet the maximum flood discharge requirements and ensure sufficient aeration conditions $[7,26]$. With the rapid rotation and diffusion of flow in the vertical shaft, the water thickness decreases and equivalently $\lambda$ increases. However, the increasing effect seems to flatten off remarkably as decreasing level $\mathrm{z}$.

The minimum $\lambda(\lambda \mathrm{m})$, a vital design parameter, can be plotted against a dimensionless discharge parameter $F_{a}\left(F_{a}=4\left(Q^{2} e /\left(g \pi^{3} D_{1}{ }^{6} \cos \beta\right)\right)^{1 / 3} /\left(1-e / D_{1}\right)\right)$ on previous experimental investigations [15] for the tangential slot inlet. Figure 9 shows the numerical predictions of $\lambda \mathrm{m}$ against $\mathrm{Fa}$ (according to [1], a value of e should be given as $0.9 \mathrm{E}$ for the elliptical tangential intake); the data of Yu and Lee [15] and Jain [7] are also extracted. It is seen that the results nearly match on one line. To estimate the minimum air-core ratio for the tangential intake, nonlinear regression was founded to fit collective data and proposed as follows:

$$
\lambda_{\mathrm{m}}=0.153 F_{a}^{2}-0.797 F_{a}+1
$$




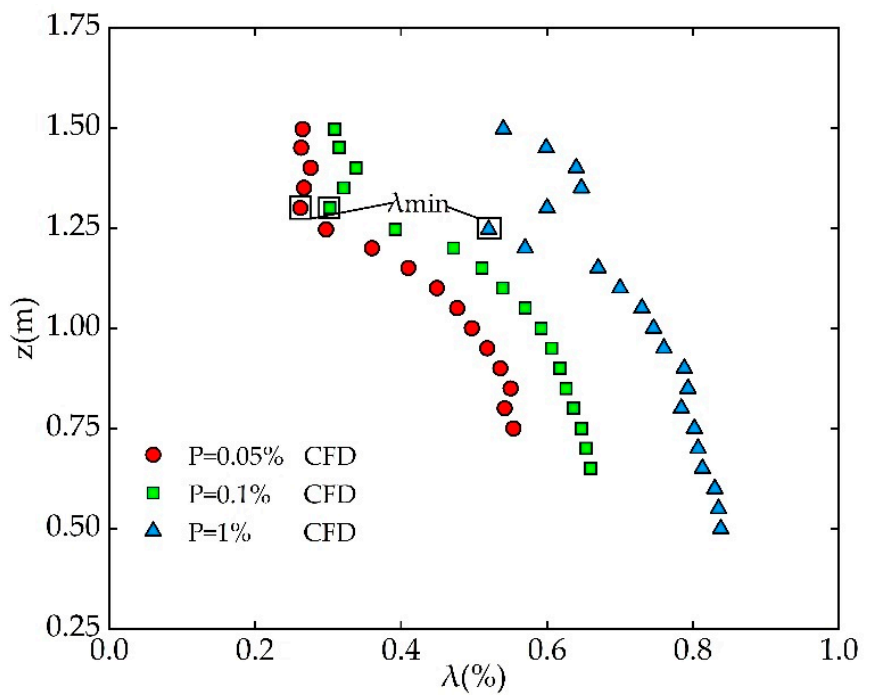

Figure 8. Air core ratio along the shaft.

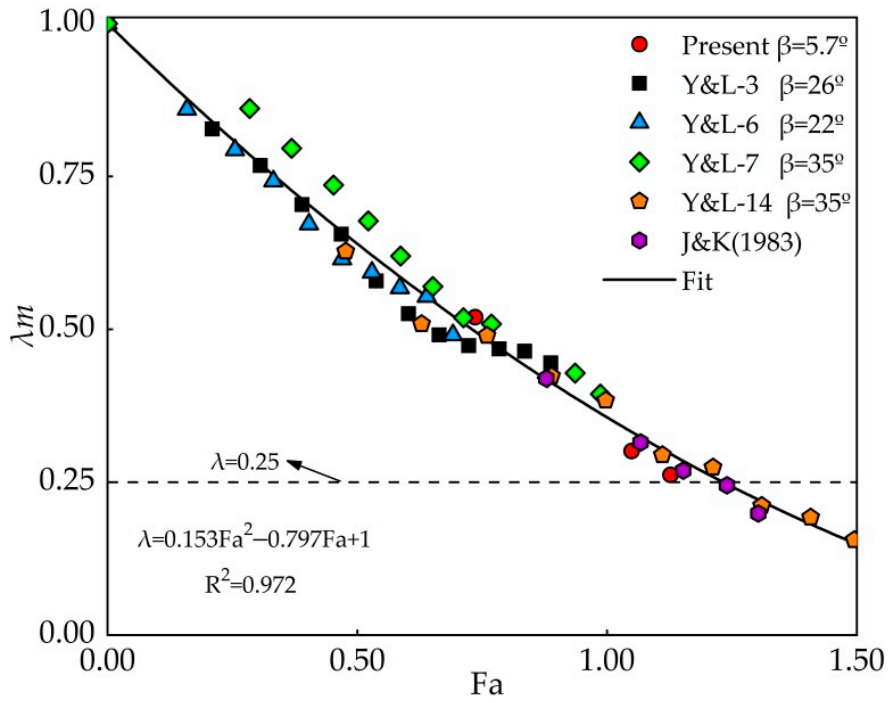

Figure 9. Minimum air-core rate against $F a$.

Equation (7) can be expected to give a satisfactory estimation of the minimum air-core rate for the VDS spillway with the tangential inlet.

\subsubsection{Annular Hydraulic Jump}

Finally, the helicoidal jet dropped into the milky hydraulic jump and formed a water cushion, consuming much energy, as shown in Figure 10. In the present experimental discharge, the pressure slope was not always submerged by the air-water mixture flow, showing a changing performance in relation to the discharge. The experimental observation shows that the condition of flow in pressure slope altering from weir flow $(\mathrm{P}=3.33 \%$, $\mathrm{Q}=17.59 \mathrm{~L} / \mathrm{s})$ to orifice flow phenomenon $(\mathrm{P}=1 \%, \mathrm{Q}=24.11 \mathrm{~L} / \mathrm{s})$. With a further increase in discharge, the free surface profile of the hydraulic jump is on the rise. 


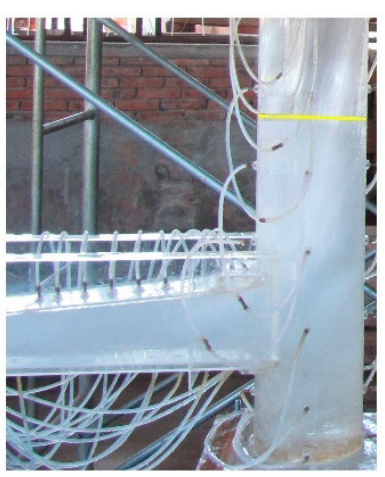

(a)

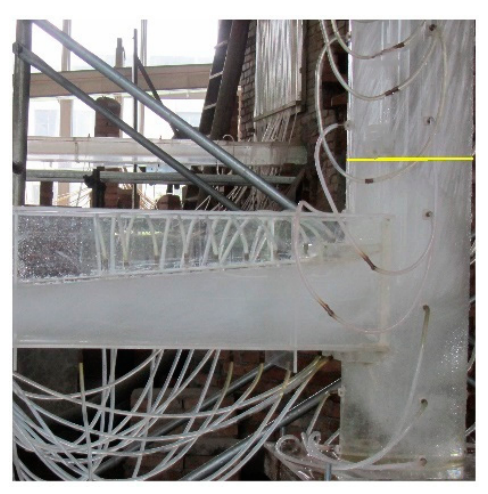

(b)

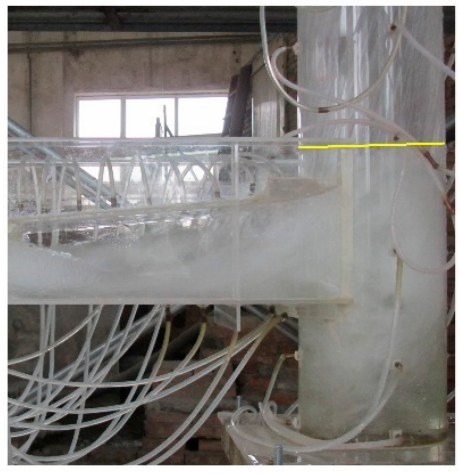

(c)

Figure 10. Experimental observation for annual hydraulic jump (a) $\mathrm{P}=0.05 \%$ (b) $\mathrm{P}=1 \%$ (c) $\mathrm{P}=3.3 \%$.

To examine the flow behavior of the annular hydraulic jump in more detail, the normalized height of the hydraulic jump $h_{j} / D_{2}$ (where $h_{j}$ is the elevation of the hydraulic jump, $D_{2}$ is the diameter of the vertical shaft.) is plotted against $Q / \sqrt{g D_{2}{ }^{5}}$ in Figure 11. In the numerical test, the annular hydraulic jump occurred at $h_{j} / D_{2}=3.60(\mathrm{P}=0.05 \%), 3.01$ $(\mathrm{P}=0.1 \%)$ and $2.4(\mathrm{P}=1 \%)$, which agreed well with experimental data under a negligible percentage error $(2.1-3.6 \%)$. For different discharges, $h_{j} / D_{2}$ increases as the $Q / \sqrt{g D_{2}^{5}}$ increases. However, $h_{j} / D_{2}$ does not shows a monotonic increasing tendency with respect to $Q / \sqrt{g D_{2}}$. It seems that $h_{j} / D_{2}$ initially increases slowly resembling with a state of weir flow when the discharge is lower than the critical value (near $Q / \sqrt{g D_{2}^{5}}=0.42$, $Q=24.11 \mathrm{~L} / \mathrm{s}, \mathrm{P}=1 \%$ ), whereas this increase becomes quickly with a trait of parabolic shape for discharge larger than these ranges. This means that the face of orifice flow is generated. The results are exactly as shown in Figure 10.

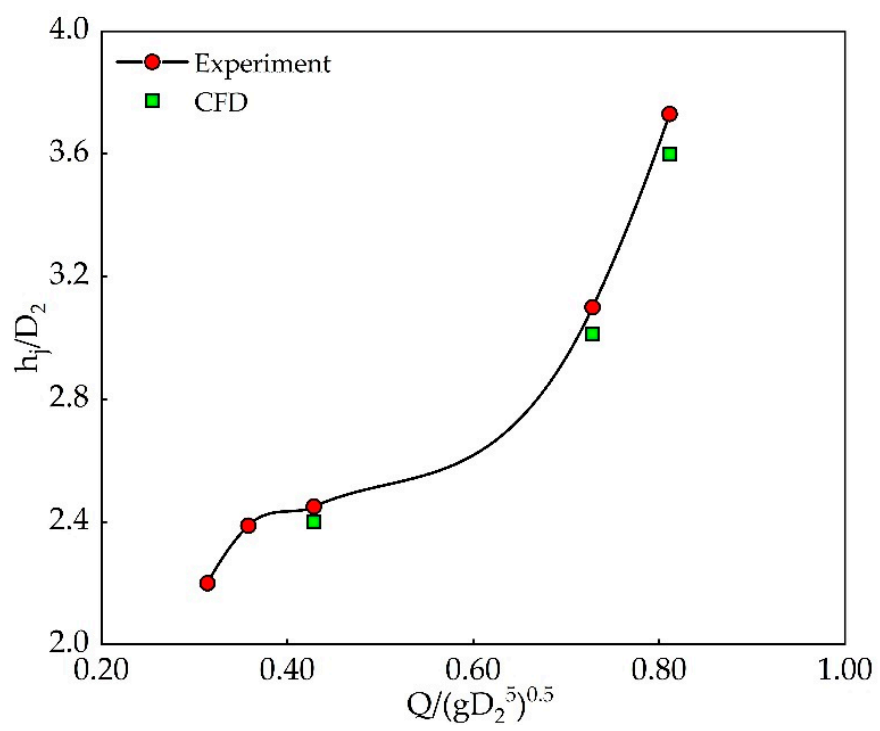

Figure 11. Relation between the normalized height of the hydraulic jump and discharge.

\subsection{Distribution of Pressure in the Vortex Drop Shaft}

\subsubsection{Wall Pressure Distribution}

The pressure corresponding to the shaft wall is one of the vital parameters to evaluate the operation safety of the VDS spillways. In order to prevent cavitation occurrence and cavitation erosion, the negative pressure area should be avoided or reduced as much as possible [24]. Figure 12 shows the measured data with corresponding simulated data of wall pressure in the VDS. It can be clearly seen that the experimental and predicted 
pressure show similar behavior with an acceptable deviation (mean error is equal to $8.07 \%$ ), which further verifies the accuracy of the numerical prediction. However, there is a significant deviation below the elevation of the annular hydraulic jump (a percentage error of 5.89-33.69\%). A reasonable explanation for this phenomenon was the measurement error caused by the rapidly up and down fluctuation of the hydraulic jump. Another explanation lied in the limitations of the VOF method for simulating vigorous air-water mixed-flow [2].

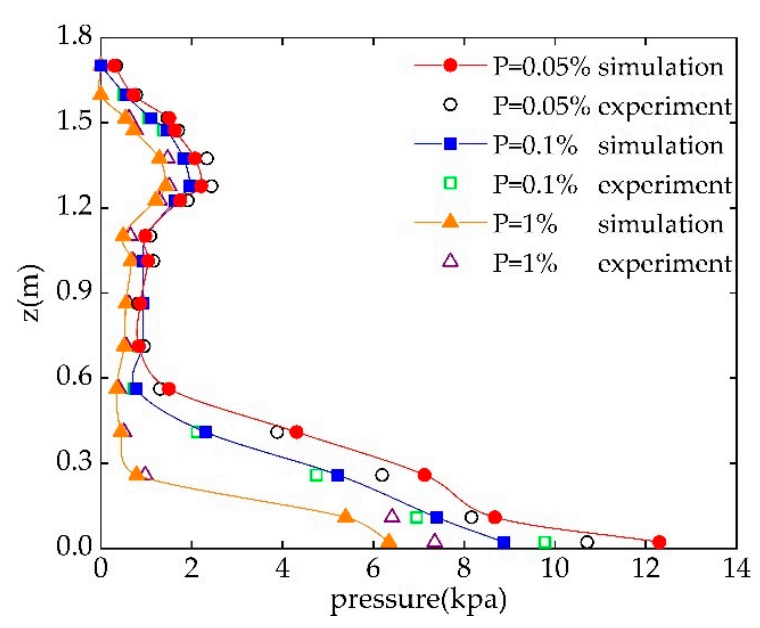

(a)

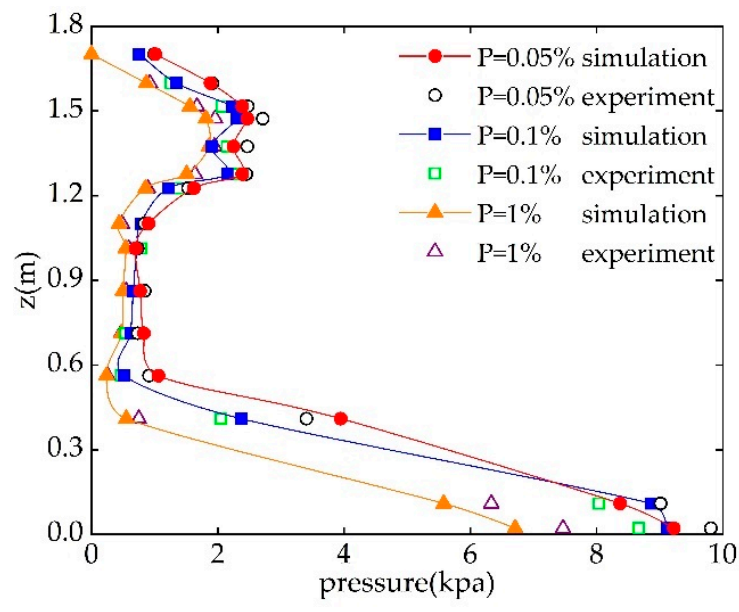

(b)

Figure 12. Experimental and predicted wall pressure in the vortex drop shaft (VDS) (a) pressure on the left wall (b) pressure on the right wall.

There was no negative pressure on the wall; the pressure distribution was asymmetrical because of uneven water thickness. The pressure initially increased from the vortex chamber to the transition section; this is due to the reason that the tapered gradient section shrinks, resulting in the increase of water thickness and tangential velocity. After this, the wall pressure above the annular hydraulic jump reduced, and the overall value was small. Finally, owing to the thickness and impingement of the water cushion, the pressure below the hydraulic jump sharply increased until the pressure reached its maximum value in the bottom of the well. The maximum value in the test was $10.76 \mathrm{kPa}$ on the left wall $(\mathrm{P}=0.05 \%)$ and $9.82 \mathrm{kPa}$ on the right wall $(\mathrm{P}=0.05 \%)$, corresponding to the simulated values of $12.34 \mathrm{kPa}$ and $9.23 \mathrm{kPa}$. After being converted to prototype, it was a relatively large value and should be paid attention to. This tendency recorded was similar to the result obtained by He et al. [27] who simulated a large-scale vortex shaft spillway with superhigh water head and large flood discharge $\left(Q>1400 \mathrm{~m}^{3} / \mathrm{s}\right)$.

\subsubsection{Cross-Sectional Pressure Distribution}

Pressure results for the different parts were obtained based on the three representative cross-sections, which are located in the vortex chamber $(\mathrm{z}=1.55 \mathrm{~m})$, the gradient section $(\mathrm{z}=1.40 \mathrm{~m})$, and the vertical shaft $(\mathrm{z}=1.10 \mathrm{~m})$, respectively. The general radial variation of the pressure cannot be obtained by experiment work but successfully captured by the numerical simulation. Figure 13 shows the cloud diagram of cross-sectional pressure, and Figure 14 drawn from the extracted node data, is the pressure distribution on the right side of the shaft axis. To avoid redundancy, the left side result that has the same variation as the right side is not considered. It can be seen from Figure 14 that the variation of pressure distribution is represented as being the smallest at the air core, approximately 0 , then gradually increasing with the increasing radius for the rotary water, and finally reaching the maximum value on the wall. Additionally, the pressure of the same cross-section with the same radius is not symmetrical because of the uneven distribution of water thickness, as seen in Figure 13. Interestingly, the pressure isoline density near the cavity is slightly 
larger than that near the shaft wall. This rather complicated behavior can be explained in terms of the adequately turbulent mixed flow at the air-water interface.

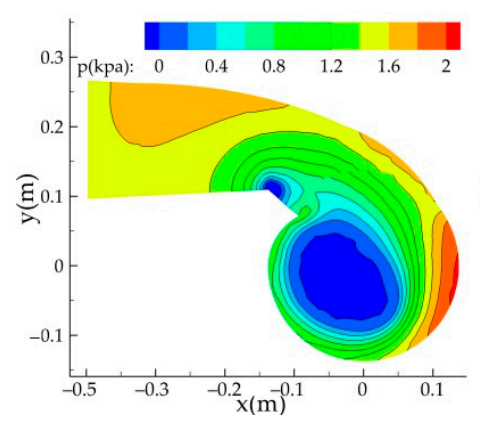

(a)

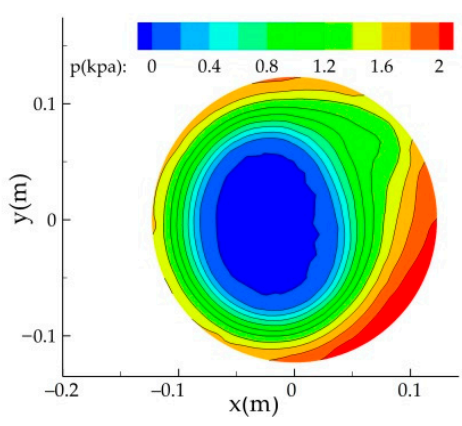

(b)

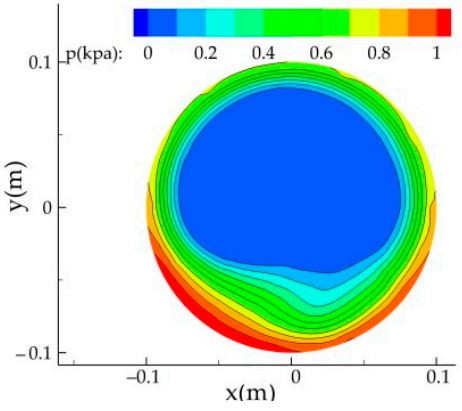

(c)

Figure 13. Pressure in different cross-section $(P=0.05 \%)$. (a) $\mathrm{z}=1.55 \mathrm{~m}(\mathbf{b}) \mathrm{z}=1.40 \mathrm{~m}(\mathbf{c}) \mathrm{z}=1.10 \mathrm{~m}$.

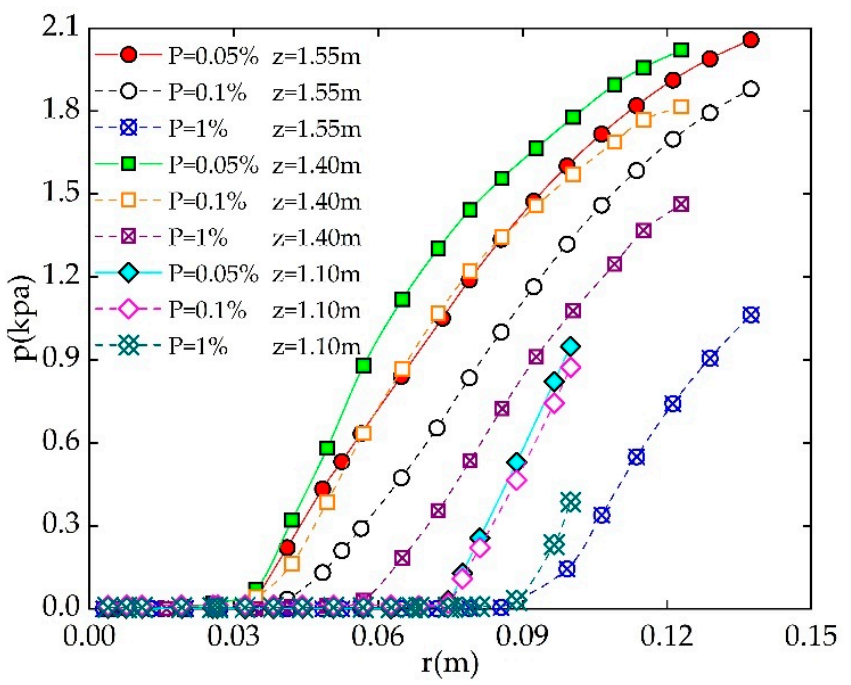

Figure 14. Pressure distribution in the radial direction.

\subsection{Three-Dimensional Velocity Field in the Vortex Drop Shaft}

The flow velocity is an important parameter when analyzing the energy dissipation effect and calculating the cavitation number. The laboratory measurement such as pitot tube has great limitations on measuring the resultant velocity in the VDS. However, Nan et al. [31] has validated the reliability for simulated velocity field When the numerical results are able to well predicts the flow pattern, the pressure, and the swirl angle (mentioned below). For this reason, the following analysis is based on numerical results.

\subsubsection{Velocity Field near the Wall}

Generally, the rotational motion within the VDS not only depends on geometric parameters such as the shape of the inlet structure, the shrinkage degree of the gradient section and the size of the vertical shaft, but also is closely linked to the turbulence and shear of flow, the mixing of the air and water, and the centrifugal force. Previous studies $[2,24,27]$ focused more on the resultant velocity rather than each velocity component. As a typical three-dimensional motion, the rotary flow motion can be decomposed into axial motion, tangential motion and radial motion, satisfying the expression as follows:

$$
v^{2}=v_{z}^{2}+v_{t}^{2}+v_{r}^{2}
$$


where $v$ denotes the resultant velocity, $v_{z}, v_{t}$ and $v_{r}$ are the axial velocity, the tangential velocity and the radial velocity, respectively.

Figure 15 shows the resultant velocity with corresponding velocity components of the swirling flow cling to the wall (the velocity extracting points are about $5-8 \mathrm{~mm}$ from the wall, and elevation corresponds to the pressure measurement point). With the exception of local fluctuation caused by shrinkage effects in the gradient section, the changing trend on both sides is basically similar under the tested discharge. The unequal values on both sides at a fixed elevation are probably due to the flow thickness and the wall friction. It is well known that with decreasing shaft elevation, gravity potential energy is gradually converted into kinetic energy, resulting in the increase in $v$ and $v_{z}$. However, once the helicoidal jet is distant from the top of the vertical shaft, the increasing rate of $v$ and $v_{z}$ is no longer obvious. Following Hager [19], the rotational flow starts maintaining quasi-uniform flow with a constant maximum velocity. This behavior seems to occur for the small discharge $(\mathrm{P}=1 \%)$, in which a stable velocity value is around $3.8 \mathrm{~m} / \mathrm{s}$, as shown in Figure 15. Dong [1] provided an approximation of maximum velocity $v_{m}$, as

$$
v_{m}=\left(\frac{8 g Q}{n \pi D_{2}}\right)^{1 / 3}
$$

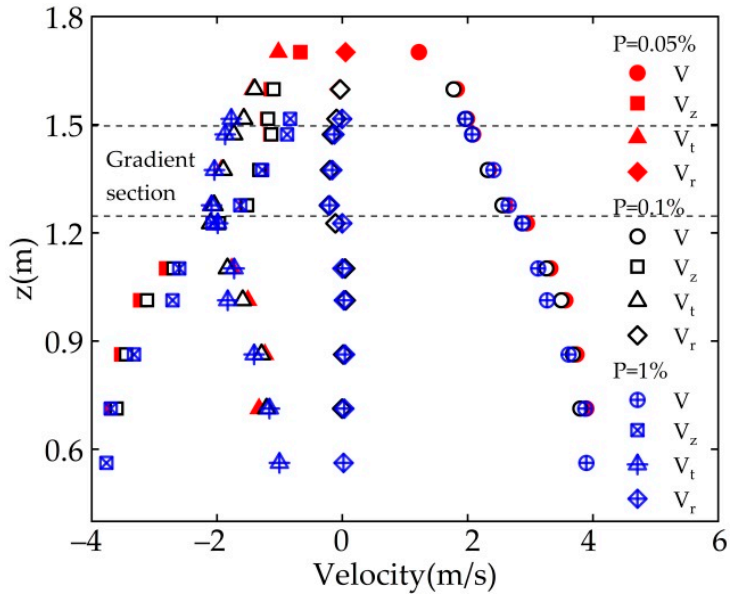

(a)

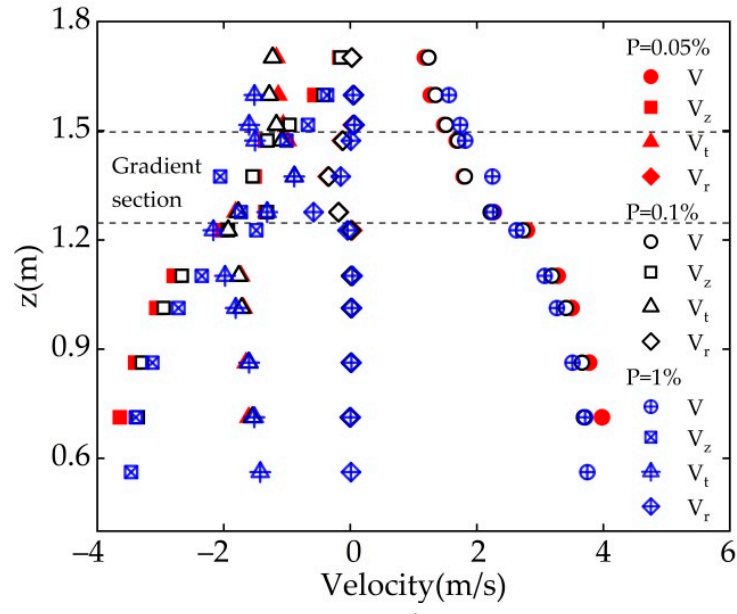

(b)

Figure 15. Velocity trends along the wall (a) left velocity (b) right velocity.

Herein $\mathrm{n}$ is the roughness coefficient; it is generally considered to be greater than the value calculated by the Manning formula [26]. This coefficient was also experimentally summarized by Dong [1] as:

$$
n=0.09+0.04 \operatorname{Exp}\left(-0.2 z / D_{2}\right)^{1 / 3}
$$

With respect to the tangential velocity, its value roughly increases at the gradient section but decreases at the vertical shaft. The reason for this increased behavior was attributed to the blocking and shrinkage effect of the gradient section, leading to the centrifugal force increases to maintain the conservation of angular momentum. After this, the tangential velocity behaves to decrease because of wall friction. In addition, it can be noted from Figure 15 that the radial velocity is negligible. Alternatively speaking, the rotational flow field in the VDS is dominated by axial and tangential movement.

\subsubsection{Swirl Angle}

So far, few analytical approaches for rotational flow angle $(\alpha)$ are available up to the authors' knowledge [2,17]. The swirl angle can be estimated as $\alpha=\arctan \left(v_{t} / v_{z}\right)$ for the 
reason that $v_{\mathrm{r}}$ the aforementioned is negligible. According to the results of swirl angle, as shown in Figure 16, the simulated values are very close to those actually obtained in the laboratory, with an acceptable error of 3.3-11.5\%. The swirl angle decreases with increasing the incoming discharge at a fixed elevation and varied approximately in the range of $15-80^{\circ}$. Specifically, the patterns of swirl angle distribution are as follows:

(1) The large swirl angle appeared at the vortex chamber, where the tangential velocity was much larger than the axial flow velocity, according to Figure 15. As the initial tangential dominant movement was transformed into a compound movement of the tangential and axial direction, the swirl angle gradually decreased along the wall;

(2) The swirl angle in the gradient section tended to fluctuate due to the complex and unstable flow field herein. This phenomenon corresponded to the noticeable fluctuation of $v_{t}$ and $v_{z}$ in Figure 15, which was beneficial to increase the local water head loss to improve the energy dissipation rate;

(3) In the vertical shaft, the tangential velocity along the shaft was gradually consumed due to friction effects, whereas the axial velocity increased because of gravity, which together reduced the swirl angle.

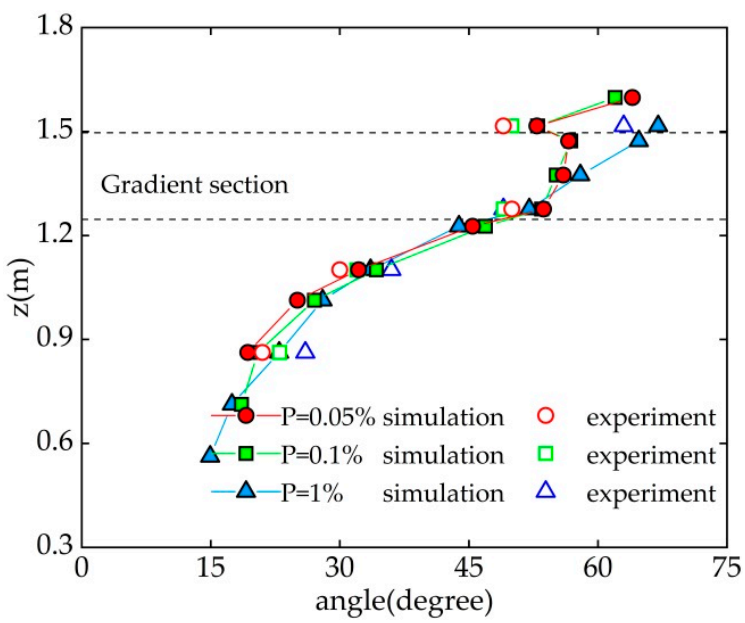

(a)

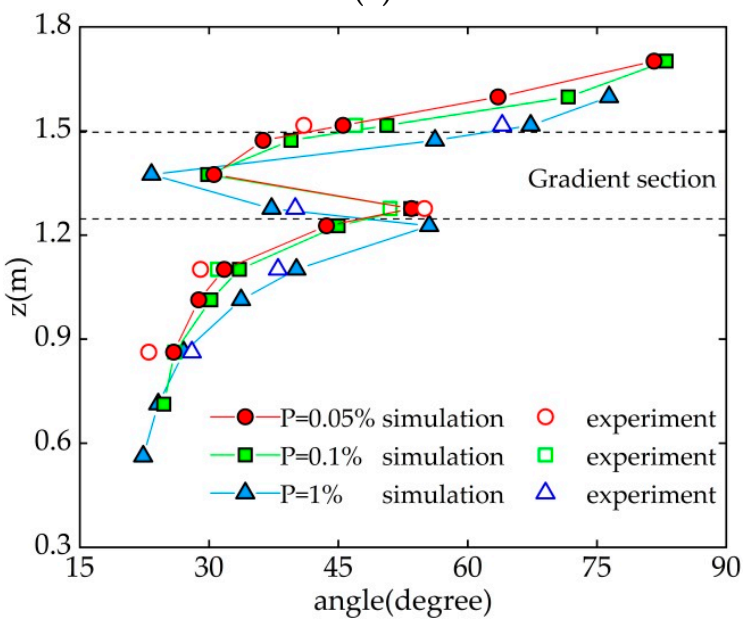

(b)

Figure 16. Swirl angle along the wall (a) left swirl angle (b) right swirl angle.

\subsubsection{Cross-Sectional Velocity Field}

(1) Resultant velocity distribution

The example representing the resultant velocity distribution along the radial direction is shown in Figure 17 at the flood frequency of $0.5 \%$. Figure 18 shows the velocity distribu- 
tion of the rotational flow (fraction of water accounting for $80 \%$ is taken as the air-water interface). Due to the similar variation of left side, only the right results are shown. It can be seen that the velocity behavior in the swirling flow area and the air core area exhibit obvious spatial variations.

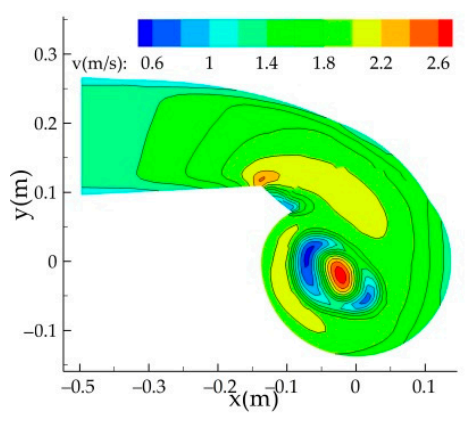

(a)

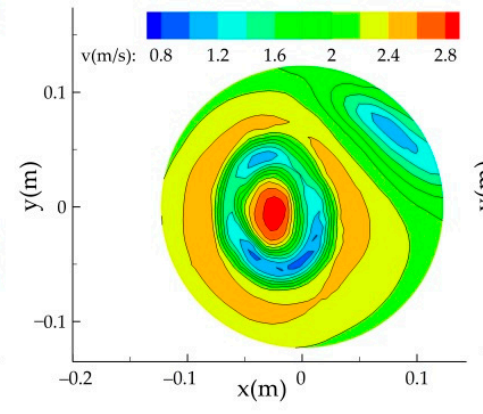

(b)

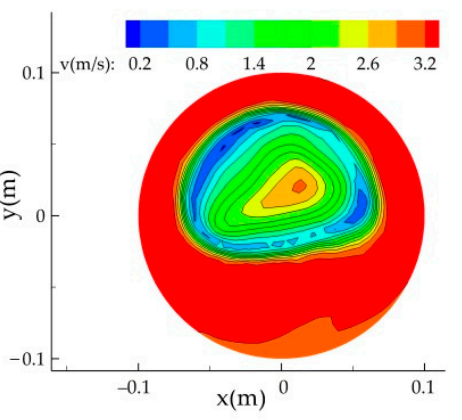

(c)

Figure 17. Resultant velocity in different cross-sections $(P=0.5 \%)(\mathbf{a}) \mathrm{z}=1.55 \mathrm{~m}(\mathbf{b}) \mathrm{z}=1.40 \mathrm{~m}(\mathbf{c}) \mathrm{z}=1.10 \mathrm{~m}$.

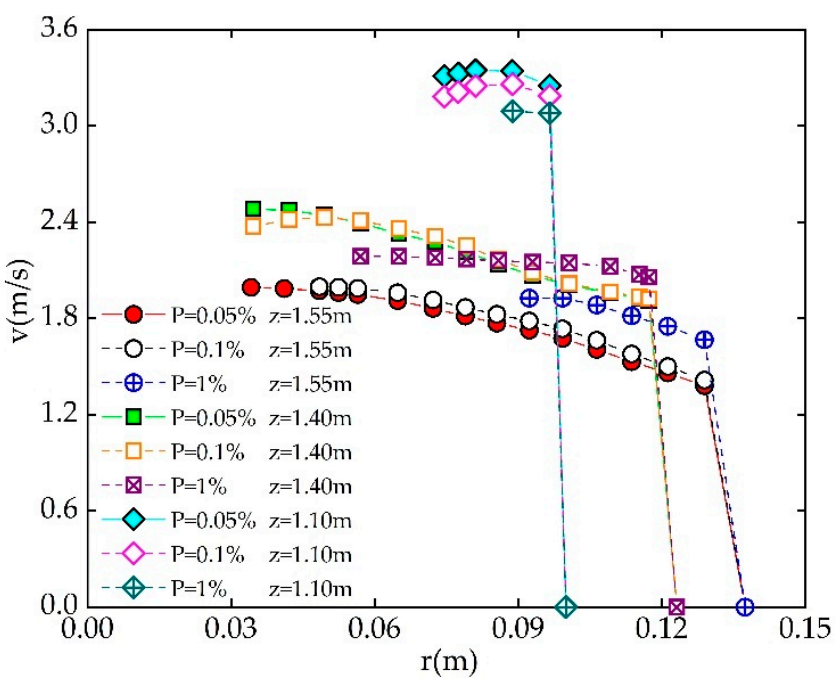

Figure 18. Resultant velocity of rotational flow along the radial direction.

For the rotational flow area, the resultant velocity gradient is much smaller than that of the air in Figure 17. On one hand, for the vortex chamber and gradient section with a thick water layer, the velocity distribution is represented as that it linearly decreases from the air-water interface due to viscous dissipation, subsequently plummets to 0 rapidly near the wall affected by the boundary condition, as shown in Figure 18. On the other hand, the distribution of resultant velocity at the vertical shaft where the water layer is relatively thin is distinctly different from that aforementioned. The resultant velocity value no longer declines at first. Instead, its value first increases and then decreases with an insignificant variation, which persuasively proves why it is reasonable to use the near-wall velocity to replace average velocity at the vertical shaft regarding the previous studies $[2,24]$.

With respect to the air, its movement is mainly caused by the entrainment of swirling water [33]. The density of velocity isoline is the largest near the air-water interface, probably because of the highly turbulent and violently mixed air and water here. Additionally, the air velocity in the cavity approximates the maximum at the center, as seen in Figure 17.

(2) Tangential velocity distribution

The tangential velocity distribution on a level rotary flow discharge tunnel is similar to that of the hydrocyclone, which is basically in line with the combined vortex distribution 
that inside and outside swirling flow are corresponding to the forced vortex distribution and free vortex distribution, respectively $[30,31,33]$. Whereas such phenomena for the VDS spillway is not clear. Therefore, the author tried to analyze and discuss the tangential velocity distribution of the rotational flow in the VDS. According to the test of Bradley and Pulling [44], the tangential velocity distribution of the forced vortex accords with the following law:

$$
\frac{v_{t}}{r^{k}}=C
$$

The distribution of free vortex conforms to the following expression:

$$
v_{t} r^{k}=C
$$

where the $k$ is an index reflecting the degree to which the swirling flow conforms to the absolute forced vortex or free vortex behavior, $0<k<1$, the closer $k$ is to 1 , the more consistent it is. $C$ is a constant on the same cross-section, but different-in-different crosssections.

Figure 19 visualizes the distribution of the tangential velocity of the swirling flow. For the vortex chamber and the contracted section, the tangential velocity increases first, with an increasing radius near the cavity, which is suggestive of a forced vortex behavior, then tends to fall off resembling a free vortex distribution near the wall, ultimately plummets to 0 affected by boundary condition. Moreover, it can be remarkably noted that the range of increase in the tangential velocity is smaller than that of decrease of the tangential velocity. This means that the tangential velocity mainly presents the free vortex distribution here. For instance, in the case of $\mathrm{P}=0.05 \%$, the ratio of increasing range to decreasing range is 1.75:1 $(\mathrm{z}=1.55 \mathrm{~m})$ and 1.83:1 $(\mathrm{z}=1.40 \mathrm{~m})$. However, for the vertical shaft, this trend remains opposite; the forced vortex area is wide because of the relatively large range of increase in the tangential velocity. For instance, in the case of $P=0.05 \%$, the ratio of increasing range to decreasing range is $0.54: 1(\mathrm{z}=1.10 \mathrm{~m})$. This finding is contrary to the previous assumption established by Jain [20], who considered the tangential velocity distribution at the vertical shaft as a free vortex region.

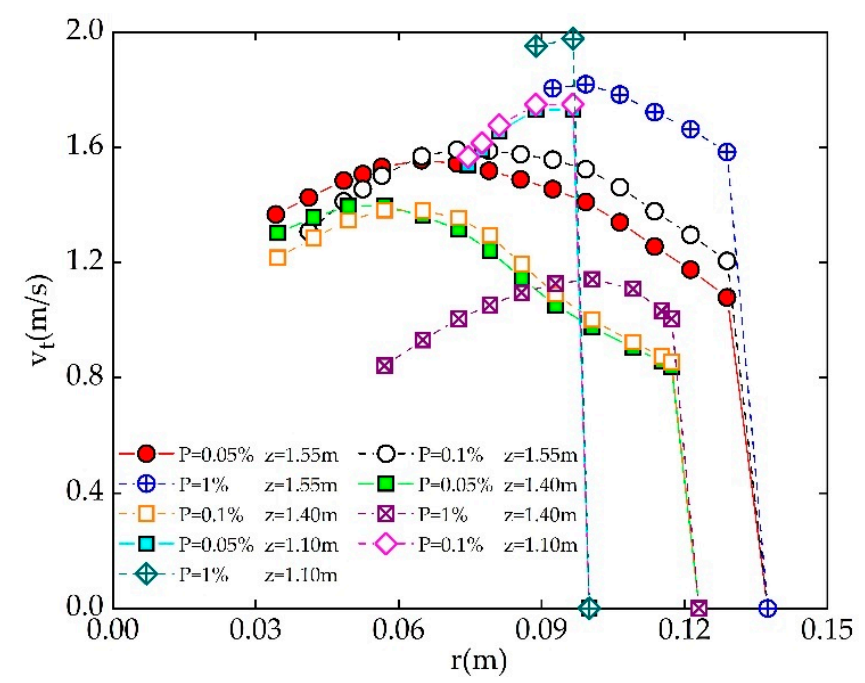

Figure 19. Tangential velocity along the radial direction.

It is significant to say that the behavior of the tangential velocity changing from quasi-forced vortex to quasi-free vortex is probably due to the reason that the violent turbulence and full mixing of the air and water at the air-water interface, making the nearcavity rotational flow more affected by the air, consequently presenting a forced vortex distribution, especially obvious when the water layer is thinner, and the cavity is larger. Hence, the tangential velocity at the vertical shaft is mainly presented as the forced vortex 
distribution. Whereas the wall friction and the water layer shear will cause the tangential velocity to be consumed, thus the near-wall tangential velocity decays freely and presents a free vortex distribution.

\subsubsection{Theoretical Analysis between Cross-Sectional Pressure and Tangential Velocity}

Herein, a predicted approach for the relationship between tangential velocity and pressure is proposed. The following calculations and results refer to the present geometry of the VDS spillway, with an elliptical tangential intake at the drop shaft head. Now using a swirling micro-surface, as shown in Figure 20. The motion Equation along the radial direction is established as follows:

$$
\left(p+\frac{\partial p}{\partial r} \times \frac{d r}{2}\right) r d \theta-\rho d r d \theta v_{t}^{2}-\left(p-\frac{\partial p}{\partial r} \times \frac{d r}{2}\right) r d \theta=\rho r d \theta d r \frac{d v_{r}}{d t}
$$

where $r$ is the radius of micro rotary flow, $d r$ is the thickness of micro rotary flow, $\frac{\partial p}{\partial r}$ is the pressure change, $d v_{r} / d_{t}$ is the radial acceleration, and $\rho$ is the density of water. Since the radial velocity is extremely small and can be ignored, Equation (13) can be simplified to:

$$
\frac{d p}{d r}=\rho \frac{v_{t}^{2}}{r}
$$

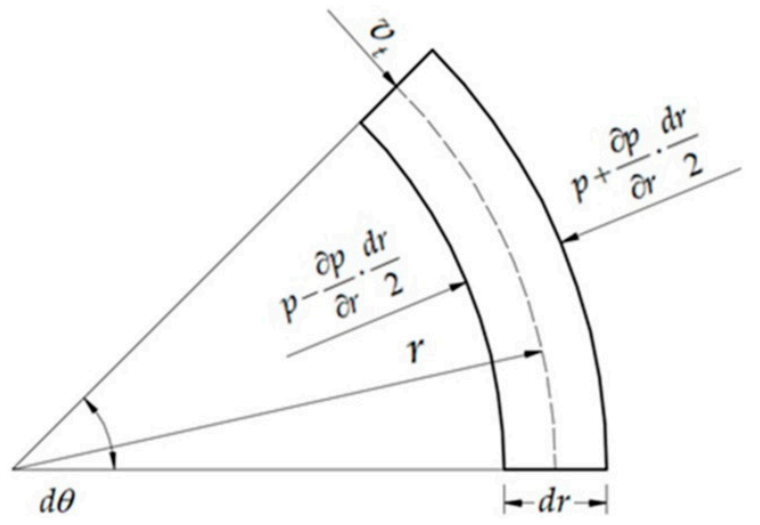

Figure 20. Analysis of the micro swirling flow.

For the near-cavity swirling flow resembling forced vortex behavior, $C$ is a constant of the same section, the Formula (11) can be expressed as:

$$
v_{t}=v_{t c}\left(\frac{r}{r_{c}}\right)^{k}
$$

where $v_{t c}$ is the tangential velocity of the swirling flow at the air-water interface, and $r_{c}$ is the corresponding radius.

Substituting Formula (15) into Formula (14) and performing integration yields:

$$
p=\frac{\rho v_{t c}^{2}}{r_{c}^{2 k}} \int r^{2 k-1} d r=\frac{\rho v_{t c}^{2}}{2 k}\left(\frac{r}{r_{c}}\right)^{2 k}+C_{1}
$$

where $C_{1}$ is the integral constant. When $r=r_{c}$, pressure is equal to 0 , Calculate $C_{1}=$ $-\rho v_{t c}{ }^{2} / 2 k$, and substitute it into Equation (16) to obtain the pressure expression of the forced vortex distribution area as follows:

$$
p=\frac{\rho v_{t c}^{2}}{2 k}\left[\left(\frac{r}{r_{c}}\right)^{2 k}-1\right]
$$


For the near-wall rotational flow resembling free vortex behavior, only Equation (12) needs to be expressed as $v_{t}=v_{t \mathrm{R}}(R / r)^{k}$. Meanwhile, the boundary conditions that $r=R, p=p_{R}$ are adopted, then the pressure expression can be obtained as:

$$
p=p_{R}+\frac{\rho v_{t R}{ }^{2}}{2 k}\left[1-\left(\frac{R}{r}\right)^{2 k}\right]
$$

where $p_{R}$ is the wall pressure, $v_{t R}$ is the corresponding tangential velocity, and $R$ is the radius of the VDS.

The $k$ value of different positions was calculated by the simulated tangential velocity. Then combined with Equations (17) and (18), the theoretical pressure at each position can be obtained. The comparison of pressure between the theoretical value and the simulated value is shown in Figure 21, where the dotted line indicates the boundary between the forced vortex and the free vortex region. It can be seen that there is a significant difference between the calculated value and the simulated value near the boundary and that the deviation within the forced vortex region is greater than that within the free vortex region. The possible reason lies in that there is a rapid adjustment of kinetic energy and pressure energy in the forced vortex region [32].

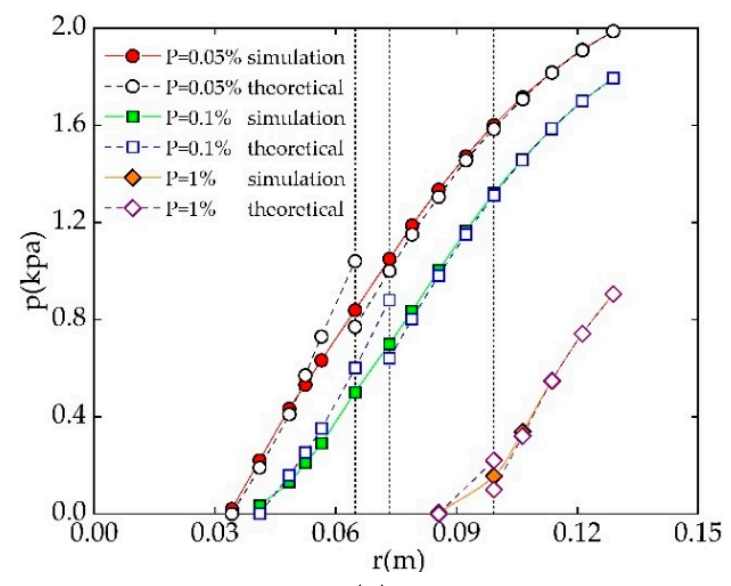

(a)

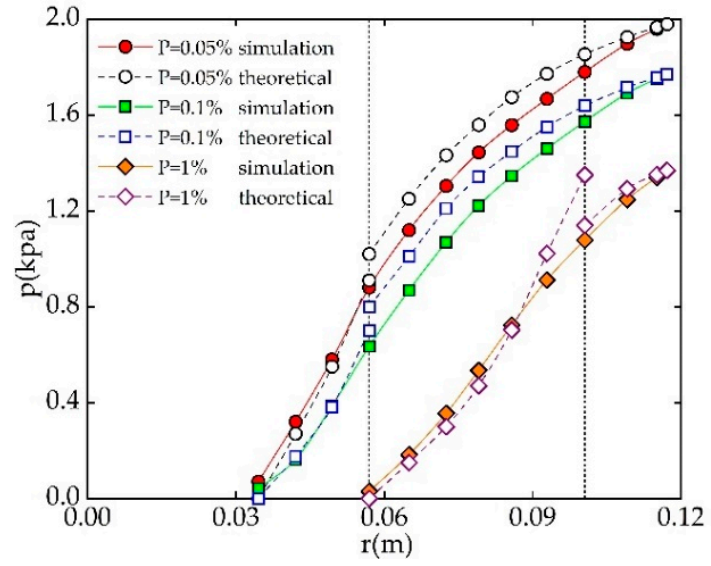

(b)

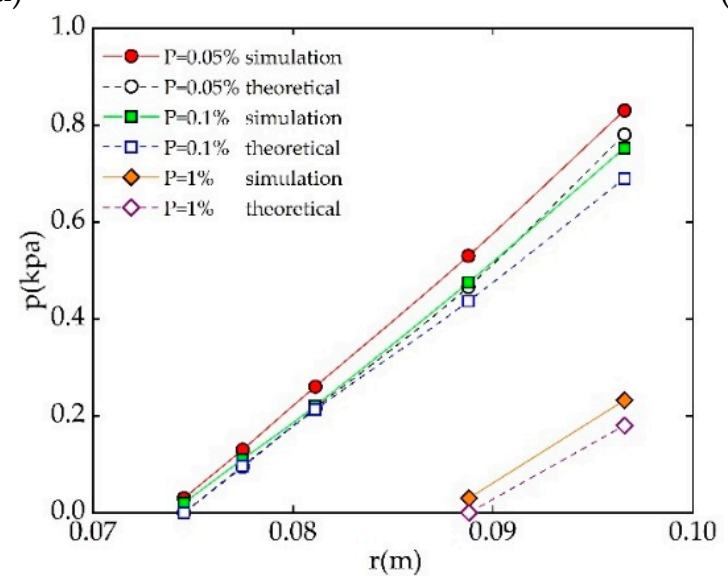

(c)

Figure 21. Comparison of the simulated values with theoretical values of the radial pressure. (a) $\mathrm{z}=1.55 \mathrm{~m}(\mathbf{b}) \mathrm{z}=1.40 \mathrm{~m}$ (c) $\mathrm{z}=1.10 \mathrm{~m}$.

The simulated and theoretical results exhibit a very similar pattern with an acceptable overall deviation at the vortex chamber $(\mathrm{z}=1.55 \mathrm{~m})$ and the gradient section $(\mathrm{z}=1.40 \mathrm{~m})$. The mean error between the calculated and simulated values was $6.96 \%$ and $7.92 \%$, respectively, while for the vertical shaft $(\mathrm{z}=1.10 \mathrm{~m})$, The mean error is $15.11 \%$, suggesting that 
the theoretical formula based on the combined vortex rule is feasible for the cross-sectional pressure prediction in the VDS spillway, especially in the free vortex region.

\section{Conclusions}

The complex flow field of a VDS spillway with an elliptical tangential inlet is tested experimentally and simulated. The results of the model experiment with corresponding numerical prediction were similar in terms of the flow pattern. The wall pressure and the swirl angle flow regime of the VDS spillway is characterized by the standing shock wave, the air core and the annular hydraulic jump. One standing wave was detected under supercritical flow conditions with a moderate Froude number. The dimensionless maximum wave height tends to linearly grow with increasing discharge, but the increasing effect is insignificantly improved. A high-axisymmetric air core along the shaft can be well captured by numerical prediction. On the basis of previous studies, a quadratic equation was fitted to give an estimation of the minimum air-core rate for the VDS spillway with the tangential inlet. As regards the annular hydraulic jump, its dimensionless height, showing variation performance of first increasing slowly and then rapidly increasing with increasing discharge, was related to the pressure slope where the flow condition varies from weir flow to orifice flow simultaneously.

The swirling flow velocity is decomposed into the three-dimensional components for detailed research. The end rotational flow seems to start maintaining quasi-uniform flow with the constant maximum resultant velocity for small discharge. The cross-sectional resultant velocity value linearly decreases with an increasing radius for the vortex chamber and gradient section while initially increases and then decreases with an insignificant variation for the vertical shaft. Moreover, the rotational flow field in the VDS is dominated by the axial and tangential movement because radial velocity with an extremely small value is negligible. The cross-sectional tangential velocity distribution accords with the combined vortex behavior. The free vortex region is wider in the vortex chamber and gradient section, but the vertical is opposite. The theoretical calculation for the cross-sectional pressure based on the combined vortex rule was developed, especially feasible in the free vortex region. Considering that the eco-friendly VDS spillway has become an important research hotspot in the field of flood discharge and energy dissipation, the current work can provide useful insights for future research and application of similar engineering. Furthermore, the relevant prototype measurements work is necessary to conduct in the future.

Author Contributions: Physical experiment, Z.Y., G.X. and H.Y.; computer and numerical simulation, Z.Y., J.Y. and Y.L.; methodology and Chart, Z.Y., J.Y. and G.X.; writing-review and editing, Z.Y., J.Y. and Z.L.; funding support, Z.L. All authors contributed to the overall framing and revision of the manuscript at multiple stages. All authors have read and agreed to the published version of the manuscript.

Funding: This research was funded by the National Natural Science Foundation of China, grant number (No. 51509212).

Institutional Review Board Statement: Not applicable.

Informed Consent Statement: Informed consent was obtained from all subjects involved in the study.

Data Availability Statement: All data, models, or code generated or used during the study are available from the corresponding author by request.

Conflicts of Interest: The authors declare no conflict of interest. 


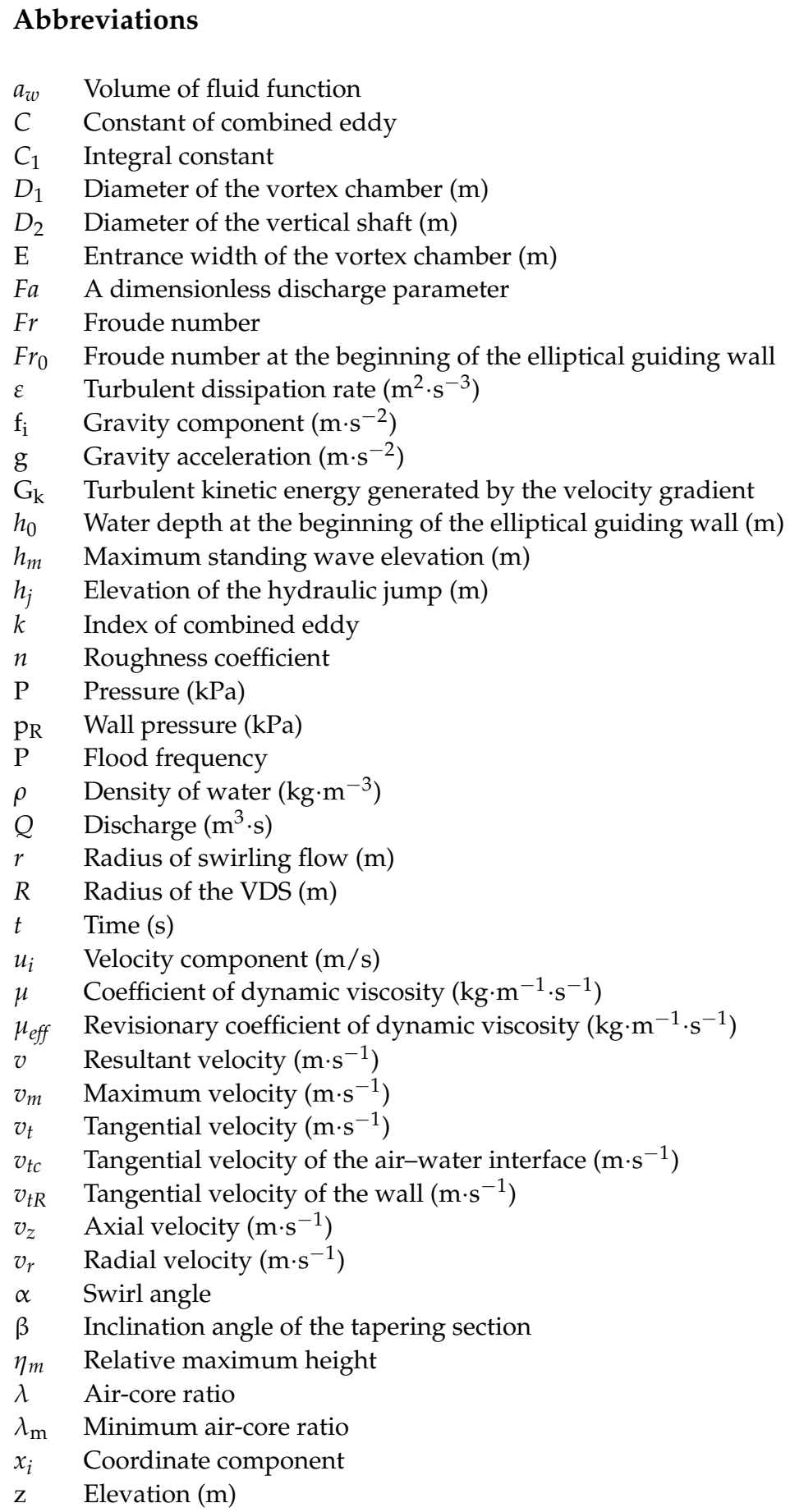

\section{References}

1. Dong, X.L. Spillway with Swirling Flow; The Yellow River Water Conservancy Press: Zhengzhou, China, 2011.

2. Liu, Z.P.; Guo, X.L.; Xia, Q.F.; Fu, H.; Wang, T. Experimental and Numerical Investigation of Flow in a Newly Developed Vortex Drop Shaft Spillway. J. Hydraul. Eng. 2018, 144. [CrossRef]

3. Lian, J.J.; He, J.L.; Guo, W.J.; Ran, D.J. Effects of Bucket Type and Angle on Downstream Nappe Wind Caused by a Turbulent Jet. Int. J. Environ. Res. Public Health 2019, 16, 1360. [CrossRef] [PubMed]

4. Dong, X.L.; Guo, J. Report on Model Study of Retrofitting a Diversion Tunnel into a Vortex Dropshaft Spillway in Shapai Power Station; IWHR Research Rep, China Institute of Water Resources and Hydropower Research: Beijing, China, 1995.

5. Sun, S.K.; Liu, Z.P.; Zhou, S.; Yang, J.W. Study on the rebuild of large-sized diversion tunnel into flood releasing tunnel in the Xiaowan Hydropower Station. Water Power 2001, 1, 26-31, 68.

6. Dong, X.L.; Yang, K.l.; Guo, X.L.; Guo, Y.X. Hydraulic mechanism and application of swirling device in morning glory shaft spillway. J. Hydraul. Eng. 2011, 42, 14-18. (In Chinese) 
7. Jain, S.C.; Kennedy, J.F. Vortex-flow Drop Structures for the Milwaukee Metropolitan Sewerage District Inline Storage System. In Proceedings of IIHR Rep.264; Iowa Institute of Hydraulic Research, University of Iowa: Iowa City, IA, USA.

8. Rhee, D.S.; Park, Y.S.; Park, I. Effects of the bottom slope and guiding wall length on the performance of a vortex drop inlet. Water Sci. Technol. 2018, 78, 1287-1295. [CrossRef]

9. Jain, S.C. Tangential Vortex-Inlet. J. Hydraul. Eng. 1984, 110, 1693-1699. [CrossRef]

10. Quick, M.C. Analysis of Spiral Vortex and Vertical Slot Vortex Drop Shafts. J. Hydraul. Eng. 1990, 116, 309-325. [CrossRef]

11. Hager, W.H. Vortex Drop Inlet for Supercritical Approaching Flow. J. Hydraul. Eng. 1990, 116, 1048-1054. [CrossRef]

12. Chan, S.N.; Qiao, Q.S.; Lee, J.H.W. On the three-dimensional flow of a stable tangential vortex intake. J. Hydro-Environ. Res. 2018, 21, 29-42. [CrossRef]

13. Pfister, M.; Crispino, G.; Fuchsmann, T.; Ribi, J.M.; Gisonni, C. Multiple Inflow Branches at Supercritical-Type Vortex Drop Shaft. J. Hydraul. Eng. 2018, 144, 9. [CrossRef]

14. Slisskii, S.M.; Kuznetsov, E.B.; Akhmedov, T.K. Multistage whirlpool shaft spillways. Hydrotech. Constr. 1980, $14,892-895$. [CrossRef]

15. Yu, D.; Lee, J.H.W. Hydraulics of Tangential Vortex Intake for Urban Drainage. J. Hydraul. Eng. 2009, 135, 164-174. [CrossRef]

16. Del Giudice, G.; Gisonni, C. Vortex dropshaft retrofitting: Case of Naples city (Italy). J. Hydraul. Res. 2011, 49, 804-808. [CrossRef]

17. Crispino, G.; Pfister, M.; Gisonni, C. Hydraulic design aspects for supercritical flow in vortex drop shafts. Urban Water J. 2019, 16, 225-234. [CrossRef]

18. Wu, J.H.; Ren, W.C.; Ma, F. Standing wave at dropshaft inlets. J. Hydrodyn. 2017, 29, 524-527. [CrossRef]

19. Hager, W.H.; Kellenberger, M.H. Die Dimensionierung Des Wirbelfallschachtes [The Design of the Vortex Drop]. Gas-und Wasserfach. Wasser Abwasser 1987, 128, 582-590.

20. Jain, S.C. Air Transport in Vortex-flow Drop Shafts. J. Hydraul. Eng. 1988, 114, 1485-1497. [CrossRef]

21. Edwini-Bonsu, S.; Steffler, P.M. Dynamics of air flow in sewer conduit headspace. J. Hydraul. Eng. 2006, 132, 791-799. [CrossRef]

22. Li, Y.; Zhang, F.X.; Deng, J.; Xu, W.L. Calculation of the Cavity Length of Annular Aerator in the Vortex Drop Shaft Spillway. J. Sichuan. Univ. 2011, 43, 28-33.

23. Gualtieri, C.; Chanson, H. Interparticle arrival time analysis of bubble distributions in a dropshaft and hydraulic jump. J. Hydraul. Res. 2013, 51, 253-264. [CrossRef]

24. Zhang, W.C.; Wang, J.X.; Dong, Z.S.; Zhou, Z.; Yang, X. Characteristics of energy dissipation and cavitation of vertical swirling spillway. J. Zhongnan Univ. 2018, 49, 3011-3019.

25. Camino, G.A.; Zhu, D.Z.; Rajaratnam, N. Flow Observations in Tall Plunging Flow Dropshafts. J. Hydraul. Eng. 2015, 141, 7. [CrossRef]

26. Zhao, C.H.; Zhu, D.Z.; Sun, S.K.; Liu, Z.P. Experimental study of flow in a vortex drop shaft. J. Hydraul. Eng. 2006, 132, 61-68. [CrossRef]

27. He, J.L.; Yin, J.B.; Jiang, Q.F.; Wu, B.Q. Numerical simulation study on vortex shaft spillway with superhigh water head and large flood discharge. J. Hydroelect. Eng. 2016, 35, 45-51.

28. Guo, Y.; Ni, H.G. Study on the water flow characteristics of the vortex shaft spillway. J. Hydrodyn. Ser. A 1995, 1, 97-105.

29. Mahmouth-Rad, M.; Khanjani, M.J. Energy Dissipation of Flow in the Vortex Structure: Experimental Investigation. J. Pipel. Syst. Eng. Pract. 2019, 10, 16. [CrossRef]

30. Cao, S.L.; Niu, Z.M.; Yang, J.; Lu, H.B. Velocity and pressure distributions in discharge tunnel of rotary-obstruction composite inner energy dissipation. Sci. Chin. Technol. Sci. 2011, 54, 111-117. [CrossRef]

31. Nan, J.H.; Niu, Z.M.; Zhang, D. Study on Velocity Characteristics of Cavity Gyrating Flow in Gyrating Discharge Tunnel. J. Sichuan Univ. 2016, 48, 41-47.

32. Niu, Z.M.; Zhang, M.Y. Wall Stress of Horizontal Rotary Cavity Flow. J. Chin. J. Appl. Mech. 2004, 4, 110-114, 174.

33. LI, Q.L.; Niu, Z.M.; Wang, J. Analysis of Rotary Flow in Spillway Tunnel with Blocking Based on Quasi-free-vortex Rules. J. Sichuan Univ. 2014, 46, 49-57.

34. Zhang, J.M.; Ren, C.Y.; Xu, W.L.; LI, Z.; HU, X.Y. Novel type of revolving-flow drop-shaft with submerged outlet. J. Hydroelect. Eng. 2012, 31, 96-101.

35. Wei, Y.; Shi, Z.J.; Chang, X.Q. Hydraulic design of vertical vortex spillway tunnel. J. Hydroelect. Eng. 2007, $26,88-92$.

36. Chen, J.G.; Zhang, J.M.; Xu, W.L.; Wang, Y.R. Scale Effects of Air-Water Flows in Stiling Basin of Multi-Horizontal Submerged Jets. J. Hydrodyn. 2010, 22, 788-795. [CrossRef]

37. Galvan, S.; Reggio, M.; Guibault, F. Assessment Study of k-epsilon Turbulence Models and Near-Wall Modeling for Steady State Swirling Flow Analysis in Draft Tube Using Fluent. Eng. Appl. Comput. Fluid. 2011, 5, 459-478. [CrossRef]

38. Li, S.; Zhang, J. Numerical Investigation on the Hydraulic Properties of the Skimming Flow over Pooled Stepped Spillway. Water 2018, 10, 1478. [CrossRef]

39. Qi, Y.; Wang, Y.; Zhang, J. Three-Dimensional Turbulence Numerical Simulation of Flow in a Stepped Dropshaft. Water 2019, 11, 30. [CrossRef]

40. Yakhot, V. Renormalization group analysis of turbulence: Basic theory. J. Sci. Comput. 1986, 1, 3-51. [CrossRef]

41. Jalil, S.A.; Hussein, B.S.; Sarhan, S.A. Visualization of elbow flow performance as shaft spillway. Ain Shams Eng. J. 2020, 11, 865-873. [CrossRef] 
42. Launder, B.E.; Spalding, D.B. A Mathematical Model Illustrating the Theory of Turbulence; Academic Press: London, UK, 1972.

43. Hirt, C.W.; Nichols, B.D. Volume of fluid (VOF) method for the dynamics of free boundaries. J. Comput. Phys. 1981, 39, 201-225.

44. Bradley, D.; Pulling, D.J. Flow pattern in the hydraulic cyclone and their interpretation in terms of performance. Trans. Inst. Chem. Engrs. 1959, 37, 34-45. 